\title{
Encapsulated Urea-Kaolinite Nanocomposite for Controlled Release Fertilizer Formulations
}

\author{
Siafu Ibahati Sempeho, ${ }^{1}$ Hee Taik Kim, ${ }^{2}$ Egid Mubofu, ${ }^{3}$ Alexander Pogrebnoi, ${ }^{1}$ \\ Godlisten Shao, ${ }^{4}$ and Askwar Hilonga ${ }^{1}$ \\ ${ }^{1}$ Department of Materials Science and Engineering, Nelson Mandela African Institution of Science and Technology, \\ P.O. Box 447, Arusha, Tanzania \\ ${ }^{2}$ Department of Chemical Engineering, Hanyang University, 1271 Sa 3-dong, Sangnok-gu, Ansan-si, \\ Gyeonggi-do 426-791, Republic of Korea \\ ${ }^{3}$ Chemistry Department, University of Dares Salaam, P.O. Box 35091, Dar es Salaam, Tanzania \\ ${ }^{4}$ Department of Chemistry, Mkwawa College of Education, University of Dar es Salaam, P.O. Box 2513, Iringa, Tanzania
}

Correspondence should be addressed to Hee Taik Kim; khtaik@hanyang.ac.kr and Askwar Hilonga; askwar.hilonga@nm-aist.ac.tz

Received 17 March 2015; Accepted 20 May 2015

Academic Editor: Manuela Curcio

Copyright (C) 2015 Siafu Ibahati Sempeho et al. This is an open access article distributed under the Creative Commons Attribution License, which permits unrestricted use, distribution, and reproduction in any medium, provided the original work is properly cited.

Urea controlled release fertilizer (CRF) was prepared via kaolinite intercalation followed by gum arabic encapsulation in an attempt to reduce its severe losses associated with dissolution, hydrolysis, and diffusion. Following the beneficiation, the nonkaolinite fraction decreased from $39.58 \%$ to $0.36 \%$ whereas the kaolinite fraction increased from $60.42 \%$ to $99.64 \%$. The X-ray diffractions showed that kaolinite was a major phase with FCC Bravais crystal lattice with particle sizes ranging between $14.6 \mathrm{~nm}$ and $92.5 \mathrm{~nm}$. The particle size varied with intercalation ratios with methanol intercalated kaolinite $>$ DMSO-kaolinite $>$ urea-kaolinite (KPDMU). Following intercalation, SEM analysis revealed a change of order from thick compact overlapping euhedral pseudohexagonal platelets to irregular booklets which later transformed to vermiform morphology and dispersed euhedral pseudohexagonal platelets. Besides, dispersed euhedral pseudohexagonal platelets were seen to coexist with blocky-vermicular booklets. In addition, a unique brain-form agglomeration which transformed into roundish particles mart was observed after encapsulation. The nanocomposites decomposed between 48 and $600^{\circ} \mathrm{C}$. Release profiles showed that $100 \%$ of urea was released in 97 hours from KPDMU while $87 \%$ was released in 150 hours from the encapsulated nanocomposite. The findings established that it is possible to use Pugu kaolinite and gum arabic biopolymer to prepare urea CRF formulations.

\section{Introduction}

In point of fact, urea is the most widely used nitrogen fertilizer in most parts of east Africa because of its high nitrogen $(\mathrm{N})$ content $(46 \%)$ and comparatively low cost of production; however, due to surface runoff, leaching, and vaporization, the utilization efficiency or plant uptake of urea is generally below $50 \%$ [1]. In fact, it is associated with up to 60 to $70 \%$ loss of the nitrogen being applied and contributes to greenhouse gases (GHG) emissions and water pollution [2] which in turn causes adverse effects during seed germination, seedling growth, and early plant growth in soil due to urea itself, to biuret and other impurities in urea fertilizers, and to products formed by hydrolysis or other transformations of urea in the soil $[3,4]$. Such limitations can be reduced by amending urea fertilizers with small amounts of either urease inhibitor [4], by encapsulation with synthetic or biopolymers, or by intercalation with nanoclays to formulate CRFs $[5,6]$.

Essentially, CRFs are prepared through encapsulation with low permeability excipients [7] using resin, wax, sulfur, polymer, silicates, and so forth, that prevents the nutrients it contains from being immediately available to the plant; as a result nutrients are released over an extended period leading to an increased control over the rate and pattern of 
nutrient release. Control over the release pattern depends on the thickness of the coatings within the formulation [8]. Precisely, CRFs exhibit superior features over traditional forms, such as decreased rate of nutrient losses from the soil by rain or irrigation water, sustained supply of nutrition for a prolonged time, increased fertilizer use efficiency (FUE), reduced frequency of application, minimized potential negative effects associated with overdosage, and reduced toxicity, thus making CRFs' manufacturing and usage inevitable in the agricultural revolution era [1]. This paper describes the application of both intercalation reactions and encapsulation mechanisms to prepare urea based CRF by using Pugu kaolinite and gum arabic biopolymer.

Archetypally, kaolinite belongs to a class of layered materials with its "crystals built by the stacking of twodimensional units known as layers that are bound to each other through weak forces" [9]. The existence of such weak forces bounding the two-dimensional layers in place to form sheets makes layered materials including kaolinite and others described elsewhere [10-14] capable of undergoing intercalation reactions. According to [9] as quoted herein, "intercalation reactions occur by topotactic insertion of mobile guest species (neutral molecules, anhydrous or solvated ions) into the accessible crystallographic defined vacant sites located between the layers (interlayer spacings) in the layered host structure. In this intercalation compounds, strong covalent bond occurs in the layers and weak interactions, between host lattice and guest species or co-intercalated solvents. Ionic and solvent exchange reactions are related to the replacement of solvated guest species (cations and anions) located into the interlayer spacings. In this case, only the solvents, the cations or the solvated cations can be replaced, depending on the reaction conditions."

Fundamentally, the term intercalation involves insertion of a guest molecule into a host lattice whereby the guesthost structure or intercalation compound is only slightly perturbed from the host structure and that the reaction used to form the compound is reversible [15]. Typically, these reactions are just topochemical processes which involve conserving the natural host lattice structure in the course of the forward and reverse reactions unlike normal solid state reactions which involve extensive bond breaking and structural reorganization and require temperatures in excess of $600^{\circ} \mathrm{C}$. For all intents and purposes as other reactions do, intercalation reactions also consist of bond breaking in the host as well as bond formation between the guest and host, a process which results in an increase in the basal spacing of the unit cell of the layer host lattice upon intercalation. In our context we refer to intercalation reactions in the layered silicates, particularly the kaolinite in the kaolin group of minerals which comprises among others nacrite, dickite, and halloysite [16] with kaolinite being the most abundant and differs from the other three members of the group by including molecular water in the interlayer [17], an inherent property which makes kaolinite suitable for undergoing intercalation reactions. Principally, kaolinite is 1:1 clay mineral consisting of two-dimensional sheets of corner sharing $\mathrm{SiO}_{4}$ tetrahedral and/or $\mathrm{AlO}_{4}$ octahedral and thereby categorized as a layered phyllosilicate capable of undergoing intercalation interactions and, so, "commonly employed in polymer/clay nanocomposites due to their swelling properties which result from their ability to hold water and other organic molecules between the silicate layers, high aspect ratio, high cation exchange capacities and large surface area" Chen et al. [18].

Generally, layered phyllosilicate based controlled release fertilizers (CRFs) are fertilizer granules intercalated within carrier molecules commonly known as excipients to control nutrients release, thereby improving nutrient supply to crops and minimizing environmental, ecological, and health hazards; consequently the excipients play a role in regulating nutrients release time and eliminating the need for constant fertilization and higher efficiency rate than conventional soluble fertilizers [6]. Precisely, CRFs usage is an advanced way to supply crop's nutrients (cf. conventional ways) due to gradual pattern of nutrient release, which improves fertilizer use efficiency (FUE) [6]. In this paper, a comprehensive investigation was done to intercalate urea fertilizer into the Pugu kaolinite interlayer spaces through a series of two intermediate consecutive stages involving dimethyl sulfoxide and methanol. Afterwards, urea fertilizer was intercalated by a way of replacing methanol intermediate complex through substitution mechanism and, finally, the urea intercalated Pugu kaolinite was encapsulated with gum arabic natural degradable biopolymer to form a crosslinked nanocomposite controlled release urea fertilizer.

\section{Materials and Methods}

Kaolinite was collected at Pugu hills in the coast region Kisarawe, Tanzania, by using quartering sampling technique described by [19]. Urea (ACS reagent, 99.0-100.5\%) was supplied by Sigma Aldrich, Acacia powder (extra pure reagent) was supplied by Junsei Chemical Co., Ltd., Japan, DMSO (Extra pure, $\geq 99.5 \%$ ) was supplied by Daejung Chemicals \& Metals, Co., Ltd., Gyeonggi-do, Korea, sodium chloride (extra pure, $\geq 99.0 \%$ ) was supplied by Samchun Pure Chemicals Co., Ltd., Gyeonggi-do, Korea, silver chloride (ACS reagent, 99.0\%) was supplied by Sigma Aldrich, methanol (extra pure, $\geq 99.5 \%$ ) was supplied by Daejung Chemicals \& Metals, Co., Ltd., Gyeonggi-do, Korea, acacia powder (extra pure reagent) was supplied by Junsei Chemical Co., Ltd., Japan, deionized distilled water (D.I. was supplied by Professor Kim's lab), and isopropanol was supplied by Daejung Chemicals \& Metals, Co., Ltd., Gyeonggi-do, Korea.

Since most raw kaolins are associated with some ironbearing and black-colored materials which limit their usability [20], beneficiation thence remains to be an inevitable process necessary for their characterization, materials synthesis, and other advanced applications related to kaolin group of minerals where kaolinite is amongst. Purification of raw Pugu kaolinite was carried out with wet beneficiation technique by simple size separation using "Classifier." The method involved the separation of fine platy kaolinite from coarse quartz, feldspar, mica, and other impurities using different setting velocities associated with particle size as governed by Stockes' law. The entire procedure which involves crushing to pulverization and soaking as well as running the classifier unit to drying has been comprehensively described in [16]. 
Beneficiated kaolinite was modified by dispersing few grams in a $0.1 \mathrm{M} \mathrm{NaCl}$ solution and treated ultrasonically at $50^{\circ} \mathrm{C}$ for 30 hours and then magnetically stirred for more 30 hours under constant stirring. The product was filtered under vacuum filter and washed several times to remove excess chloride whereas washing was stopped after negative reaction with $\mathrm{AgNO}_{3}$. The washed product was dried in a vacuum oven at $60^{\circ} \mathrm{C}$ and stored as NaKP.

Intercalating dimethyl sulfoxide (DMSO) into the kaolinite interlayer spaces was done as follows. A measured amount of Pugu kaolinite in a given volume of distilled water (D.I.) was mixed with DMSO solution in a ratio of $1: 6: 1$, respectively, and then agitated in a magnetic stirrer for 21 days at $80^{\circ} \mathrm{C}$ with a very small addition of water droplets to hinder desiccation of the stirring mixture. After 21 days of continuous stirring the suspension was aged for one week by way of stirring at room temperature. The resultant suspension was then washed with excess isopropanol and dried at $60^{\circ} \mathrm{C}$ in a vacuum oven. The powdered product obtained was labeled KPDMSO. By using KPDMSO powder as a starting material, $2 \mathrm{~g}$ was taken and dispersed in a $60 \mathrm{~mL}$ of methanol solution followed by a 5 -day stirring at RT. After 5 days of continuous stirring the suspension was left to mature over the weekend and, afterward, washing with isopropanol was done. The washed preparation was then dried at $60^{\circ} \mathrm{C}$ in a vacuum oven; the product in powder form obtained was named KPDM.

Preparation of urea-kaolinite intercalated fertilizer formulation was carried via urea-methanol replacement mechanism. Methanol intercalated kaolinite (KPDM) was used as a starting material where a 1:1 ratio of this intermediate intercalation compound and urea was dispersed in a $60 \mathrm{~mL}$ of methanol solvent and then stirred for 5 days at $40^{\circ} \mathrm{C}$. After 5 days of continuous stirring, excess isopropanol was used to wash the intercalation compound obtained in order to get off unreacted matter and impurities. The new urea fertilizer produced was labeled KPDMU and dried at $40^{\circ} \mathrm{C}$ in a vacuum oven to remove excess solvent. For the purpose of preparing urea based nanocomposite CRF formulation, acacia powder was employed as an encapsulating material to crosslink the urea-kaolinite intercalation compound. To the starting material (KPDMU), few grams was shaken with acacia powder in a ratio of $1: 2$ in a vessel containing $60 \mathrm{~mL}$ methanol as a solvent and then stirred for 150 hours at room temperature. Subsequently, the nanocomposite material obtained was filtered in a vacuum oven and dried at $40^{\circ} \mathrm{C}$ to dryness and kept for analysis as KPDMUG. As pointed out elsewhere [21, 22], the apparent intercalation ratio (AIR) was determined as shown in the following equation:

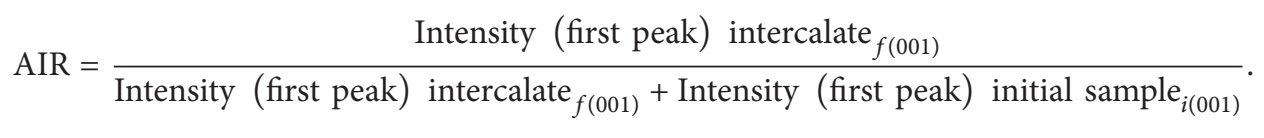

Generally, a diffraction pattern must first be indexed before being analyzed. Indexing was done by first determining the unit cell parameter from the peak position and then Miller indices due to the fact that diffraction pattern is a direct result of two things: (i) the size and shape of the unit cell which determine the relative position of the diffraction peak and (ii) the atomic position within the unit cell which determines the relative intensities of the diffraction peaks. The details of the procedures used for indexing [23] consist of six steps: (i) peak identification, (ii) determining $\operatorname{Sin}^{2} \theta$, (iii) calculating the ratio of $\operatorname{Sin}^{2} \theta / \operatorname{Sin}^{2} \theta_{\text {min }}$, multiplied by the appropriate integers, (iv) determining the integer values of $h^{2}+k^{2}+l^{2}$, (v) identifying the Bravais lattice from the Miller indices, and (vi) calculating the lattice parameters. Determination of the estimate crystallite size was performed with X-ray diffraction pattern by using Scherrer equation:

$$
\beta(2 \theta)=\frac{K \lambda}{L \cos \theta},
$$

where $K$ is Scherrer constant for shape factor values, $\lambda$ is wavelength of X-radiation, $\theta$ is half the diffraction angle, $\beta$ is peak width, and $L$ is the crystallite size [24]. According to [24], the most common $K$ values include 0.94 for Full Width at Half Maximum (FWHM) of spherical crystals with cubic symmetry, 0.89 for integral breath of spherical crystals with cubic symmetry, and 1 because 0.94 and 0.89 both round up to 1 as well as the values of 0.62 to 2.08 because of variation in K.
Characterization of the samples involved was done as follows. FTIR-ATR measurements were performed in the near infrared region at wavelength between 7500 and $360 \mathrm{~cm}^{-1}$ using a Bruker Optic GmbH (alpha model, Laser class 1) Spectrometer with attenuated total reflectance (ATR). XRD patterns of raw and beneficiated Pugu kaolinite for mineralogical characterization were executed on SIEMENS $\mathrm{D}-5005 \mathrm{X}$-ray Diffractometer using $\mathrm{Cu} \mathrm{K} \alpha 1$ radiation. The $2 \theta$ scan range was between $2^{\circ}$ and $65^{\circ}$. On the other hand, the $\mathrm{XRD}$ patterns for the intercalation compounds as well as the nanocomposites were performed using Rigaku Corporation D/MAX-2500/PC X-ray Diffractometer equipped with a back monochromator operating at $40 \mathrm{kV}$ and $100 \mathrm{~mA}$ at the scanning range of $5^{\circ}-80^{\circ}$ with a step size of $0.1^{\circ}$ and a time/step of $1 \mathrm{~s}$ using copper cathode as the X-ray source $(\lambda)(1.54056 \AA)$. Thermogravimetry measurements of samples were taken using TG/STA Linseis STA PT 1000 simultaneous TG/DTG thermal analyzer at a scanning rate of $5^{\circ} \mathrm{C}$ per min from room temperature to $800^{\circ} \mathrm{C}$ under nitrogen atmosphere. The samples surfaces morphology was investigated by using Field Emission Scanning Electron Microscopy (SEM-Hitachi-s4800 , Japan). The accelerated voltage was $15 \mathrm{kV}$. The chemical composition of the raw materials was determined by X-ray Fluorescence (XRF) using the semiquantitative XRF analysis technique (Siemens SRS 3000 X-ray Fluorescence) (Rhodium anode, 8 analyzer crystals with beryllium windows $125 \mu \mathrm{m}$ ). The technique used is as we have described in our other 
TABLE 1: Effect of beneficiation on the distribution of raw kaolinite particles.

\begin{tabular}{lcc}
\hline Sample & $\begin{array}{c}\text { Percentage weight of particles (\%) } \\
\geq 63 \mu \mathrm{m}\end{array}$ & $\leq 63 \mu \mathrm{m}$ \\
\hline Raw Pugu kaolin & 39.58 & 60.42 \\
Beneficiated Pugu kaolin & 0.36 & 99.64 \\
\hline
\end{tabular}

TABLE 2: Mineralogical composition of the raw materials.

\begin{tabular}{lll}
\hline Sample & Major phase & Minor phase \\
\hline $\begin{array}{l}\text { Original } \\
\text { kaolin }\end{array}$ & Kaolinite & Quartz $\left[\mathrm{SiO}_{2}\right]$ \\
& {$\left[\mathrm{Al}_{2} \mathrm{Si}_{2} \mathrm{O}_{5}(\mathrm{OH})_{4}\right]$} & Microcline $\left[\mathrm{KAlSi}_{3} \mathrm{O}_{8}\right]$ \\
\hline \multirow{3}{*}{$\begin{array}{l}\text { Beneficiated } \\
\text { kaolin }\end{array}$} & $\mathrm{Kaolinite}_{2}$ & Clinochlore \\
& {$\left[\mathrm{Al}_{2} \mathrm{Si}_{2} \mathrm{O}_{5}(\mathrm{OH})_{4}\right]$} & {$\left[\mathrm{Mg}_{5} \mathrm{Al}(\mathrm{Si}, \mathrm{Al})_{4} \mathrm{O}_{10}(\mathrm{OH})_{8}\right]$} \\
& & Illite \\
& & {$\left[\mathrm{KAl}_{2}\left(\mathrm{Si}_{3} \mathrm{AlO}_{10}\right)(\mathrm{OH})_{2}\right]$} \\
\hline
\end{tabular}

recently published paper [25]. For the raw kaolinite sample the analysis of particle size distribution was carried out by using subsieve analysis technique which involves the application of Andreasen pipette sedimentation method. The details of the procedures are found in our recent article [25].

\section{Results and Discussion}

3.1. Effect of Beneficiation on the Distribution of Kaolinite Particles. The distribution of particles in the original and beneficiated Pugu kaolinite (Table 1) revealed that $39.58 \%$ was a rejected portion since it was constituted with a nonkaolinite portion of particles greater than $63 \mu \mathrm{m}$ which was not our interest since it was constituted of the nonkaolinite particles; $60.42 \%$ was the kaolinite fraction contained particles below $63 \mu \mathrm{m}$ which was the anticipated working range because it was constituted of mostly kaolinite particles. Upon beneficiation trials, there was a significant improvement in the distribution of particles; the nonkaolinite fraction was reduced to $0.36 \%$ from the $39.58 \%$ of the nonbeneficiated portion, whereas the particles below $63 \mu \mathrm{m}$ constituted $99.64 \%$ as compared to $60.42 \%$ of the nonbeneficiated portion. Essentially, it is necessary to note that the results from beneficiation trials revealed the fact that the method used was efficient and effective since there was a significant substantial reduction of nonkaolinite fraction from $39.58 \%$ of the raw Pugu kaolinite to $0.36 \%$ of the beneficiated Pugu kaolinite.

3.2. Kaolin Mineralogy. The randomly oriented whole rock $\mathrm{X}$-ray diffraction analysis for both the original Pugu kaolin and the beneficiated Pugu kaolin revealed the mineral contents present as seen in Table 2. Based on the whole rock powder mount diffractograms of raw Pugu kaolin the clay portion was only kaolinite while the nonclay portion or rather mineral impurities present in the kaolin were quartz $\left(\mathrm{SiO}_{2}\right)$, clinochlore $\left[\mathrm{Mg}_{5} \mathrm{Al}(\mathrm{Si}, \mathrm{Al})_{4} \mathrm{O}_{10}(\mathrm{OH})_{8}\right]$, and microcline $\left[\mathrm{KAlSi}_{3} \mathrm{O}_{8}\right]$. An observation made in the diffractograms of beneficiated kaolin is that the clay portion contained kaolinite $\left[\mathrm{Al}_{2} \mathrm{Si}_{2} \mathrm{O}_{5}(\mathrm{OH})_{4}\right]$, illite $\left[\mathrm{KAl}_{2}\left(\mathrm{Si}_{3} \mathrm{AlO}_{10}\right)(\mathrm{OH})_{2}\right]$, and clinochlore $\left[\mathrm{Mg}_{5} \mathrm{Al}(\mathrm{Si}, \mathrm{Al})_{4} \mathrm{O}_{10}(\mathrm{OH})_{8}\right]$ accompanied with the disappearance of quartz and microcline. According to [19] the formation of illite is generally favored by alkaline conditions and by high concentrations of $\mathrm{Al}$ and $\mathrm{K}$. It was mentioned that the appearance of illite in the beneficiated kaolin may be a result of reaction between $\mathrm{Al}$ and $\mathrm{K}$ from microcline and water, thereby causing weathering of silicates. The case may also be the same for clinochlore [17], but that may involve introduction of some $\mathrm{Mg}$ impurities during wet beneficiation trails. Although the $\mathrm{pH}$ of water used during beneficiation was not checked, it is suspected that the $\mathrm{pH}$ also contributed to this clay minerals transformation because the solubility of alumina is $\mathrm{pH}$ dependent and silica solubility increases parallel with the increase in $\mathrm{pH}$ [17]. Since the results from oriented air dried samples above were not enough to confirm the clay mineral groups obtained, it was therefore necessary to perform oriented clay analysis by $\mathrm{X}$ ray diffraction method as untreated air-dried, glycolated, and heated at $550^{\circ} \mathrm{C}$ for two hours on the original and beneficiated kaolin samples with the aim of distinguishing layer types and clay mineral groups. When the air-dried samples were diffracted, peaks were developed on the diffractograms which revealed three main clay minerals, namely, kaolinite, illite, and clinochlore. Identification and hence confirmation of these clay minerals were achieved from the differences on the diffractograms obtained by glycolating the samples and drying them; then diffraction process was carried out, and the samples were heated at $550^{\circ} \mathrm{C}$ for two hours prior to the diffraction process [19]. This behavior of stability in chemical treatment (glycolated) and heat transformation (at $550^{\circ} \mathrm{C}$ ) confirmed the presence of illite [26]. However, when the samples were glycolated, dried, and diffracted some peaks were shifted in some samples. But on heating the samples at $550^{\circ} \mathrm{C}$ followed by diffraction, these shifted peaks collapsed. This characteristic of altering the diffraction patterns is a distinguishing characteristic of kaolinite group [26]. Shortly, the mineralogical analysis test on the clay fraction revealed that the major content on both the original and beneficiated kaolin samples was kaolinite subordinated with illite.

3.3. Chemical Composition. The chemical composition of both raw and beneficiated Pugu kaolinite used in this study is given in Table 3. As can be seen that beneficiation process was very successful, there was a reduction of silica content from 63.64 to $54.99 \%$ upon beneficiation whereas alumina content got increased from 31.43 to $40.2 \%$. Variations in the composition of other oxides were also noticed as depicted in Table 3; however, a peculiar observation was that the amounts of $\mathrm{TiO}_{2}$ and $\mathrm{Fe}_{2} \mathrm{O}_{3}$ instead of getting decreased upon beneficiation were seen to increase from $0.8 \%$ and $1.01 \%$ to $1.02 \%$ and $2 \%$, respectively, whereas the amount of $\mathrm{MnO}$ was seen to be unaffected with beneficiation process employed.

3.4. XRD Analysis. The calculated lattice parameters from the indexing procedures are given in Table 4 . Based on the sequence of $h^{2}+k^{2}+l^{2}$ values, most $h k l$ reflections allowed are either all even or all odd; thus, the Bravais lattice was FCC. The average lattice parameter was $19.35 \AA$. 
TABLE 3: Chemical composition of the raw materials.

\begin{tabular}{|c|c|c|c|c|c|c|c|c|c|c|c|c|c|}
\hline \multirow{2}{*}{ Sample } & \multicolumn{13}{|c|}{ Oxide composition } \\
\hline & $\mathrm{SiO}_{2}$ & $\mathrm{Al}_{2} \mathrm{O}_{3}$ & $\mathrm{Na}_{2} \mathrm{O}$ & $\mathrm{MgO}$ & $\mathrm{SO}_{3}$ & $\mathrm{Cl}$ & $\mathrm{K}_{2} \mathrm{O}$ & $\mathrm{CaO}$ & $\mathrm{TiO}_{2}$ & $\mathrm{Cr}_{2} \mathrm{O}_{3}$ & $\mathrm{MnO}$ & $\mathrm{Fe}_{2} \mathrm{O}_{3}$ & LOI \\
\hline Pugu kaolin & 63.64 & 31.43 & 0.43 & 0.16 & 0.25 & 0.76 & 1.39 & 0.06 & 0.8 & 0.03 & 0.01 & 1.01 & 0.03 \\
\hline Beneficiated kaolin & 54.99 & 40.2 & 0.09 & 0.13 & 0.08 & 0.04 & 0.96 & 0.04 & 1.02 & 0.04 & 0.01 & 2 & 0.4 \\
\hline
\end{tabular}

TABLE 4: Indexed XRD patterns.

\begin{tabular}{lccccccccc}
\hline Peak number & $2 \theta$ & $\operatorname{Sin}^{2} \theta$ & $1 * \operatorname{Sin}^{2} \theta / \operatorname{Sin}^{2} \theta_{\min }$ & $2 * \operatorname{Sin}^{2} \theta / \operatorname{Sin}^{2} \theta_{\min }$ & $3 * \operatorname{Sin}^{2} \theta / \operatorname{Sin}^{2} \theta_{\min }$ & $h^{2}+k^{2}+l^{2}$ & $h k l$ & $a(\AA)$ & $d(\mathrm{~nm})$ \\
\hline 1 & 12.54 & 0.011933 & 2.5191 & 5.0382 & 7.5573 & 8 & 220 & 19.95 & 0.715 \\
2 & 24.85 & 0.046302 & 9.7745 & 19.5491 & 29.3236 & 29 & 520 & 19.28 & 0.358 \\
3 & 12.55 & 0.011950 & 2.5227 & 5.0454 & 7.5681 & 8 & 220 & 19.93 & 0.705 \\
4 & 24.90 & 0.046482 & 9.8125 & 19.6251 & 29.4376 & 29 & 520 & 19.24 & 0.357 \\
5 & 7.89 & 0.004737 & 1.0000 & 2.0000 & 3.0000 & 3 & 111 & 19.39 & 1.119 \\
6 & 23.59 & 0.041768 & 8.8174 & 17.6348 & 26.4522 & 27 & 333 or $511 \quad 19.22$ & 0.377 \\
7 & 8.04 & 0.004913 & 1.0372 & 2.0743 & 3.1115 & 3 & 111 & 19.04 & 1.099 \\
8 & 23.60 & 0.041805 & 8.8252 & 17.6504 & 26.4756 & 27 & 333 or $511 \quad 19.21$ & 0.377 \\
9 & 8.14 & 0.005034 & 1.0627 & 2.1254 & 3.1881 & 3 & 111 & 18.81 & 1.086 \\
10 & 22.34 & 0.037540 & 7.9248 & 15.8497 & 23.7745 & 24 & 422 & 19.48 & 0.398 \\
& & & & & & FCC Bravais sequence & \\
\hline
\end{tabular}

TABLE 5: Indexing XRD pattern: Bragg's equation.

\begin{tabular}{|c|c|c|c|c|c|}
\hline Peak number & $\operatorname{Sin} \theta$ & $d(\mathrm{~nm})$ & $1 / d^{2}$ & $\left(1 / d^{2}\right) z$ & $h k l$ \\
\hline 1 & 0.1092399 & 0.7265 & 1.8947 & 2 & 110 \\
\hline 2 & 0.21518 & 0.3580 & 7.8025 & 10 & 310 \\
\hline 3 & 0.109318 & 0.7046 & 2.0143 & 3 & 111 \\
\hline 4 & 0.215596 & 0.3573 & 7.8331 & 10 & 310 \\
\hline 5 & 0.068825 & 1.1192 & 0.7983 & 1 & 100 \\
\hline 6 & 0.204371 & 0.3769 & 7.0396 & 9 & 300 \\
\hline 7 & 0.070091 & 1.0990 & 0.82795 & 1 & 100 \\
\hline 8 & 0.204464 & 0.3767 & 7.0471 & 9 & 300 \\
\hline 9 & 0.070949 & 1.0857 & 0.8484 & 1 & 100 \\
\hline \multirow[t]{2}{*}{10} & 0.193753 & 0.3976 & 6.3257 & 8 & 220 \\
\hline & & & & \multicolumn{2}{|c|}{ FCC Bravais sequence } \\
\hline
\end{tabular}

By using Bragg's equation under assumption that " $n$ " is unit to confirm the results obtained with the six-step method, Table 5 was created whose sequence also suggested an FCC Bravais lattice. Similarly, the X-ray diffraction results reveal that the intercalation reactions were successful and, so, Pugu kaolinite can be used as CRF excipients for urea based fertilizers. This is evidenced with the fact presented in Figure 1 where intercalation of DMSO into the kaolinite interlayer spaces to form a pale yellow KPDMSO composite was achieved at the intercalation ratio of about $89.2 \%$ and that the basal lattice space for the first peak of the prepared kaolinite-DMSO nanocomposite was $1.12 \mathrm{~nm}$ which represents a lattice expansion of $0.41 \mathrm{~nm}$ as compared to the originally beneficiated Pugu kaolinite which had a basal spacing of $0.71 \mathrm{~nm}$. Similarly, methoxy intercalated kaolinite (KPDM) presented in Figure 2 had the intercalation ratio of about $87.4 \%$ and basal lattice parameter for the first peak of the prepared kaolinitemethanol nanocomposite was $1.10 \mathrm{~nm}$ which represents a lattice expansion of $0.39 \mathrm{~nm}$ in relation to the beneficiated Pugu kaolinite. Furthermore, when kaolinite was treated with urea fertilizer, the resulting urea intercalated kaolinite (KPDMU) presented in Figure 3 had the intercalation ratio of about $91.10 \%$ and basal spacing of $1.09 \mathrm{~nm}$ which signify that the lattice parameter had been stretched out to distance of $0.38 \mathrm{~nm}$ as related to the beneficiated kaolinite. A closer look at the salt modified kaolinite (NaKP), a unique phenomenon was observed; basal spacing of the beneficiated kaolinite did shrink (instead of being expanded) to a distance of about $0.0005 \mathrm{~nm}$ which represents a difference of the basal lattice parameter of $0.7047 \mathrm{~nm}$ and $0.7052 \mathrm{~nm}$ for the modified kaolinite and the beneficiated kaolinite, respectively. Fundamentally, intercalation reactions were successful in the order of KPDM > KPDMSO > KPDMU. DMSO being a strong intercalant as compared to methanol and urea, the trend was expected to be KPDMU > KPDM > KPDMSO; the reason for an increased intercalation ratio for the KPDMU can be attributed to the fact that "in the dynamic intercalation process, kaolinite and urea in the mixer suffer from the action of high-speed stirring and high temperature. The shear force produced by the intense stirring accelerates delamination of crystal layers of kaolinite and increases the intercalation reaction speed of urea into kaolinite," thereby stimulating the movement of urea molecules which in turn intensify the contact probability between urea molecules and kaolinite; as a result, the intercalation ratio is increased and so the trend was altered [22]. Thus, via DMSO-kaolinite intercalate as an intermediate, prepared by using salt treated kaolinite, urea fertilizer was intercalated into the kaolinite interlayer spaces by displacing methanol. The intercalated urea-kaolinite was then encapsulated with gum arabic to make the urea based CRF formulation. 


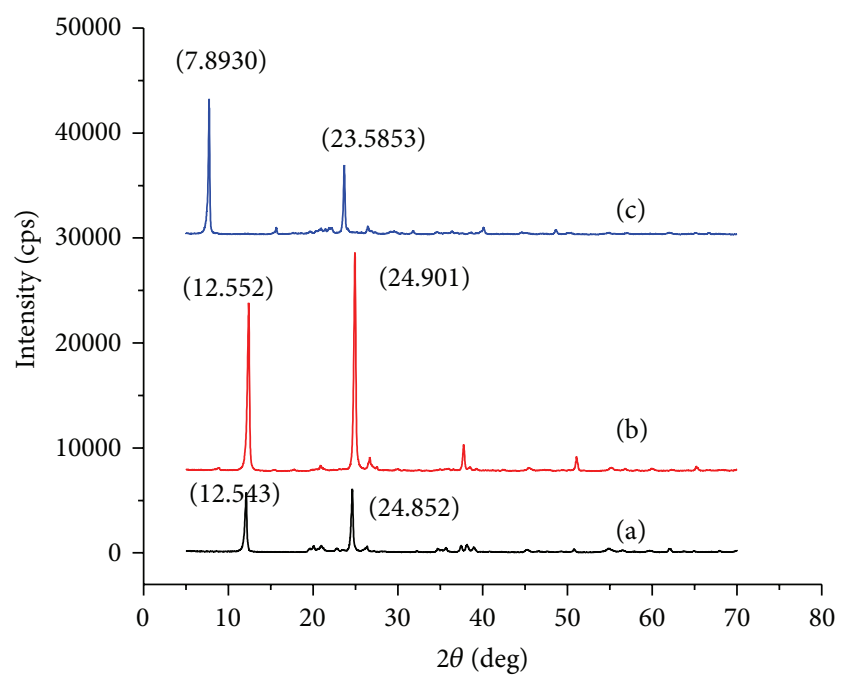

FIgURE 1: X-ray diffractograms of (a) beneficiated Pugu kaolinite, (b) NaKP, and (c) KPDMSO.

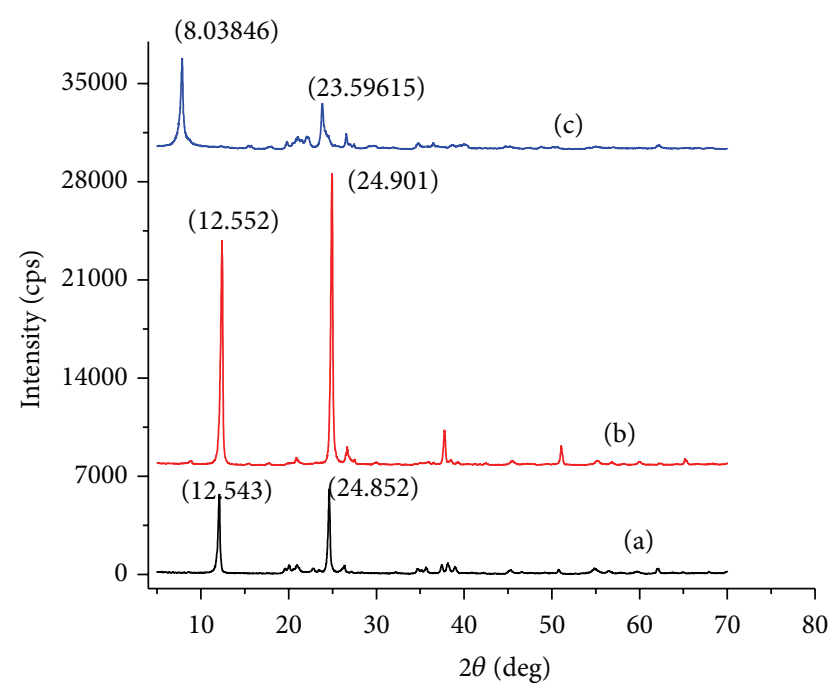

FIgure 2: X-ray diffractograms of (a) beneficiated Pugu kaolinite, (b) NaKP, and (c) KPDM.

TABLE 6: Analysis of particle sizes from Scherrer equation.

\begin{tabular}{lccccc}
\hline \multirow{2}{*}{ Sample } & \multicolumn{5}{c}{ Crystallite size (nm) } \\
& $K=2.08$ & $K=1$ & $K=0.94$ & $K=0.89$ & $K=0.62$ \\
\hline KPDMSO & 92.46 & 44.45 & 41.79 & 39.56 & 27.56 \\
KPDM & 48.81 & 23.47 & 22.06 & 20.88 & 14.55 \\
KPDMU & 50.84 & 24.44 & 22.98 & 21.75 & 15.16 \\
\hline
\end{tabular}

3.5. Particle Size Analysis. The particle sizes determined for the intermediate intercalation compounds (KPDMSO and KPDM), urea intercalated kaolinite CRF (KPDMU), and the nanocomposite CRF formulation (KPDMUG) are given in Table 6. Since our work was based on cubic systems, the best particles selected are those whose shape factor values include 0.94 and 0.89 together with their extreme cases, thereby coming to our conclusion of deciding to report a range of

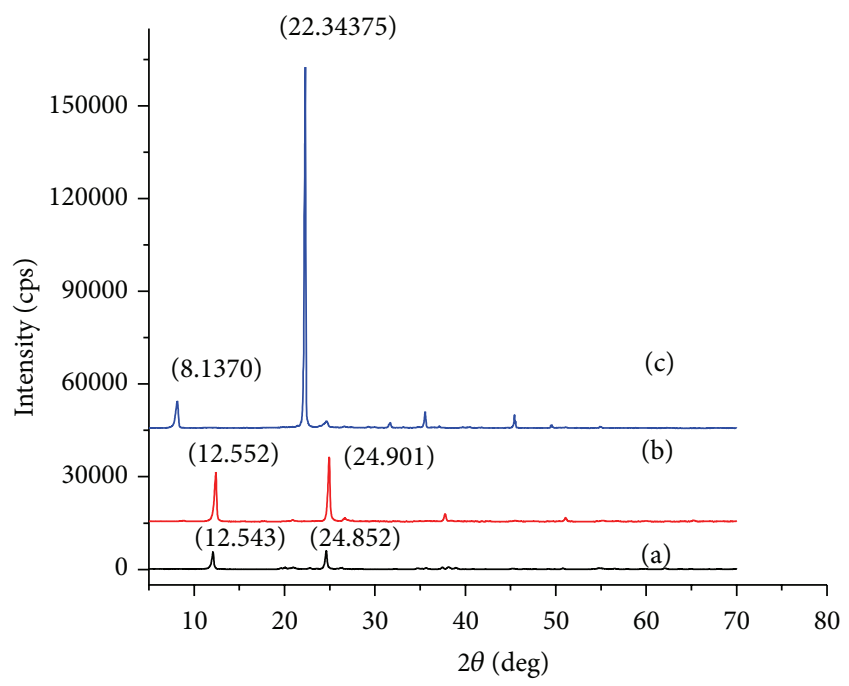

Figure 3: X-ray diffractograms of (a) beneficiated Pugu kaolinite, (b) NaKP, and (c) KPDMU.

sizes. The sizes for DMSO intercalated kaolinite nanoparticles were in a range of $27.56-92.46 \mathrm{~nm}$, whereas those of methanol intercalated kaolinite nanoparticles were in a range of 14.55$48.81 \mathrm{~nm}$ and those from urea-kaolinite CRF formulation were found to be between 15.16 and $50.84 \mathrm{~nm}$. Precisely, nanoparticles from KPDMSO were twice as bigger than the rest for the reason not yet clear to us, but an assumption we have is that this might be contributed by the size and structural pattern of DMSO.

3.6. SEM Analysis. A detailed analysis on the SEM images was carried out on the beneficiated kaolinite (KKK), NaKP, KPDMSO, KPDM, and KPDMU samples. Typically, the SEM images in Figure 4 reveal the presence of a layered morphology common to kaolinite minerals; however, the appearance of these morphologies was seen to fluctuate with kaolinite modifications. The beneficiated kaolinite was characterized with predominantly wider and thick compact overlapping euhedral pseudohexagonal platelets (Figure 4(a)); this concurs with [27]. A change in the stacking sequence of kaolinite layers was observed upon chemical treatment with $\mathrm{NaCl}$, where there occurred a mixture of irregular crystallites and thin very compacted layers appearing like booklets (Figure 4(b)). That is to say, NaKP exhibited many stacked thin euhedral pseudohexagonal platelets and part vermiform shaped particles. However, both beneficiated kaolinite and the salt treated kaolinite exhibited a high degree of crystallinity and stacking of the kaolinite particles which corresponds to kaolinite mineral [28]. As a matter of fact, the hexagonal faces of these particles correspond to the crystallographic (001) basal planes [29]. As expected, most particles were highly anisometric with thickness along the $z$ axis, much smaller than their other dimensions $[29,30]$. Our observation is, when kaolinite was harshly treated with salts particularly, $\mathrm{NaCl}$ a change in the order of arrangement of kaolinite occurred such that the surface area for intercalation is increased due to well arrangements of functional layers. 


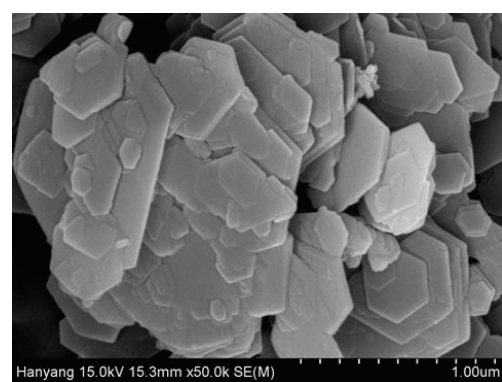

(a)

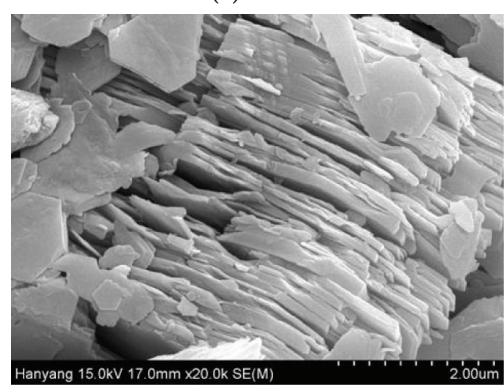

(ci)

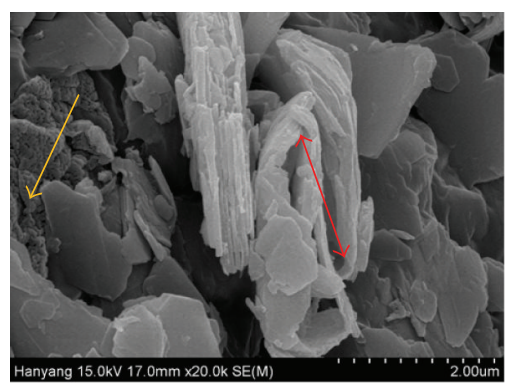

(di)

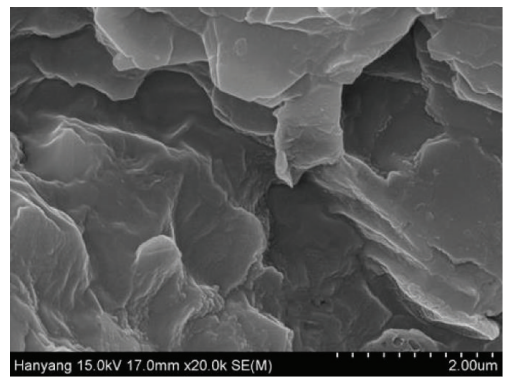

(ei)

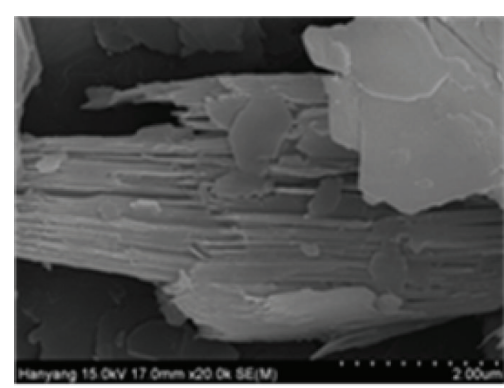

(bi)



(cii)

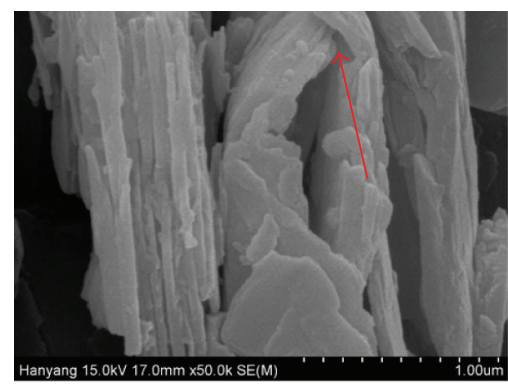

(dii)

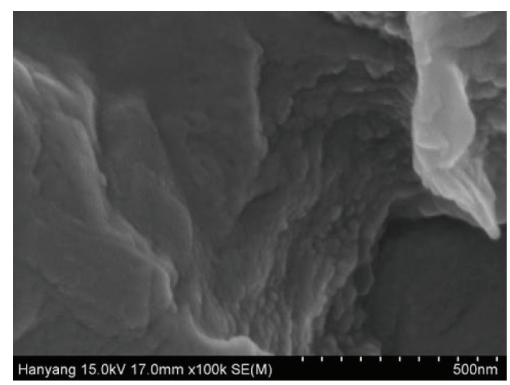

(eii)

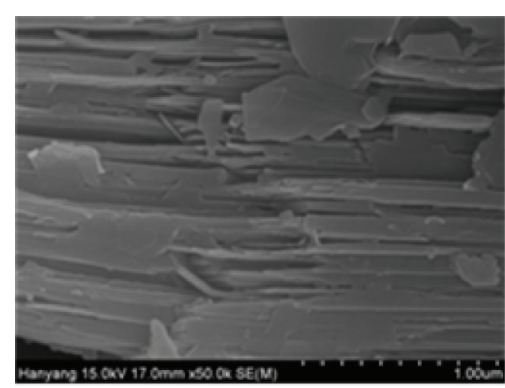

(bii)

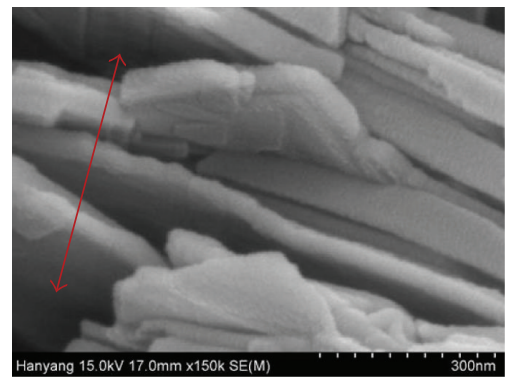

(ciii)

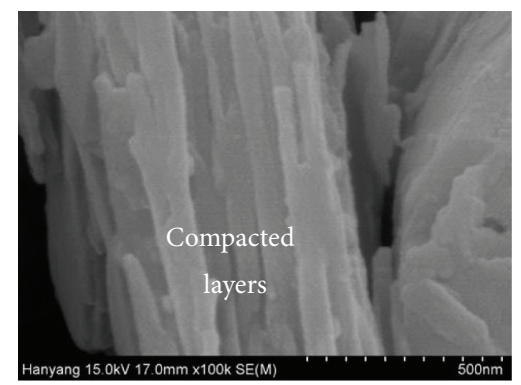

(diii)

FIgURE 4: SEM images for (a) beneficiated Pugu kaolinite (KKK), (b) NaKP, (c) KPDMSO, (d) KPDM, and (e) KPDMU.

Similarly, it was observed that particles with pseudohexagonal morphology in NaKP predominates over those with vermiform morphology; a similar observation was found by [31].

Moreover, the DMSO intercalated kaolinite exhibited a decreased compactness between layers where the distance was widened (Figure 4(c), red arrow). For the most part, vermicular booklet morphology characterized the DMSO intercalated kaolinite with a very small appearance of the dispersed euhedral pseudohexagonal platelets. A similar observation though in a different setting made Baeufort to conclude that "aggregates of kaolin with blocky habits coexist with vermicular booklets," an observation which we have considered to be valid in this work [31]. Such observation made us to sense that under certain conditions the appearance of vermiforms mixed with either stacked or dispersed euhedral pseudohexagonal platelets should be expected. When methanol replaced DMSO to form KPDM in the kaolinite interlayer spaces the following features were observed (Figure 4(d)): (i) the distance between layers had shrunk as compared to distances observed in DMSO intercalated kaolinite (Figure 4(diii)), (ii) a further decrease 
of the appearance of the blocky aggregates with euhedral pseudohexagonal platy morphology indicating an increased number of clean layers available for intercalation reactions was observed, (iii) the vermicular booklets were seen to show bending forms in some parts (red arrows), and (iv) an appearance of well-coordinated roundish agglomerated particles resembling brain morphology was seen and we named this phenomena "brain-form agglomeration" which we believe could further facilitate intercalations (orange arrow). Furthermore, a complete disappearance of both dispersed euhedral pseudohexagonal platelets, vermicular booklets as well as brain-form agglomeration, was observed in the nanocomposite KPDMUG (Figure 4(e)) when the urea intercalated kaolinite was encapsulated with acacia powder and, instead, the surface' morphology was observed to exhibit smooth mat at lower magnification which in the higher magnification the appearance was that of numerous small round particles assembled in a mat (Figure 4(eii)).

3.7. FT-IR Analysis. Treated kaolinite and beneficiated Pugu kaolinite are represented in Figures 5 and 6, respectively. A close view at these figures reveals that the vibrations occurring at $3683 \mathrm{~cm}^{-1}$ of the treated kaolinite and $3684 \mathrm{~cm}^{-1}$ of beneficiated kaolinite correspond to the in-phase $\mathrm{OH}$ stretching of the inner surface hydroxyl of the kaolinite [3235], whereas the vibrations seen at $3650 \mathrm{~cm}^{-1}$ are ascribed to the out-phase $\mathrm{OH}$ stretching vibrations of the inner surface hydroxyl groups. The bands exhibited at $3618 \mathrm{~cm}^{-1}$ are characteristic of inner layer $\mathrm{OH}$ stretching due to $\mathrm{Al}$ $\mathrm{O}-\mathrm{H}$ stretching vibrations of alumina of the kaolinite in the octahedral configuration while the characteristic $\mathrm{OH}$ stretching vibrations of the kaolinite in a tetrahedral configuration is exhibited at frequencies $749 \mathrm{~cm}^{-1}$ of the treated kaolinite [33] and is due to Si-O-Si symmetrical stretching [36]. The band seen at $1113 \mathrm{~cm}^{-1}$ is ascribed to the apical Si-O stretching mode and this is consistent with the band frequencies of $1112 \mathrm{~cm}^{-1}$ reported by [37]. While this was ascribed to SiO normal to the planar stretching, the absorption band observed at 1023 to $997 \mathrm{~cm}^{-1}$ for the treated kaolinite and $995 \mathrm{~cm}^{-1}$ for the beneficiated kaolinite corresponds to the Si-O planar stretching which in fact concurs with 1025 to $995 \mathrm{~cm}^{-1}$ reported by [32]. To be more precise, the bands at $1023 \mathrm{~cm}^{-1}$ represent the in-plane $\mathrm{Si}-\mathrm{O}$ planar stretching and $997 \mathrm{~cm}^{-1}$ or $995 \mathrm{~cm}^{-1}$ represents the out-phase $\mathrm{Si}-\mathrm{O}$ planar stretching $[32,34,35]$ and the alternating Si-O and Al-O bonds [36]; this is in close agreement to the $995 \mathrm{~cm}^{-1}$ obtained by [36] and the $997 \mathrm{~cm}^{-1}$ obtained by [38]. Another band seen at $910 \mathrm{~cm}^{-1}$ for the treated kaolinite and $909 \mathrm{~cm}^{-1}$ for the beneficiated kaolinite which closely relates to others of similar range reported in the literature such as $913 \mathrm{~cm}^{-1}$ [34], $907 \mathrm{~cm}^{-1}$ [36], $912 \mathrm{~cm}^{-1}$ [35], and 907 [39] is attributed to the $\mathrm{OH}$ deformation of inner hydroxyl groups due to the $\mathrm{Al}-\mathrm{OH}$ bending [34]. Elsewhere, this band was ascribed to the Al$\mathrm{OH}$ bending mode of kaolinite [36], $\mathrm{Al}^{(\mathrm{VI})}-\mathrm{OH}$ vibrations [35], and $\mathrm{Al}^{(\mathrm{VI})}-\mathrm{OH}$ vibrations [39]. The band at $788 \mathrm{~cm}^{-1}$ is ascribed to the Al-O-Si asymmetric bending of the bonds whereas the bands at $525 \mathrm{~cm}^{-1}$ and $520 \mathrm{~cm}^{-1}$ for the modified



FIGURE 5: ATR-FTIR spectrum of NaKP.

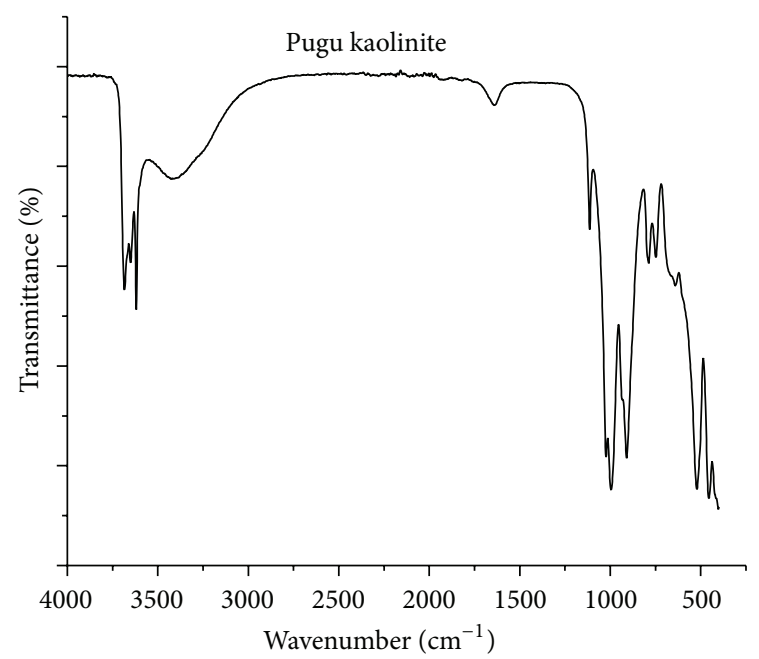

FIGURE 6: ATR-FTIR spectrum of beneficiated Pugu kaolinite.

and beneficiated kaolinite, respectively, are given to the Si$\mathrm{O}-\mathrm{Al}(\mathrm{VI})$ where $\mathrm{Al}^{3+}$ is in octahedral coordination $[36,39$, 40]. When you compare the diagrams for both beneficiated and treated kaolinite, one can easily notice a total identity between them. However, for the beneficiated kaolinite, we noticed the presence of a new broader absorption band at $3412 \mathrm{~cm}^{-1}$ which was absent in the treated kaolinite. This band corresponds to the peak maxima for water due to $\mathrm{O}-\mathrm{H}$ stretching vibration and it is observed to be broader owing to the hydrogen bonding after wet beneficiation process [41-43]. Substantially, this band can be assigned to a combination of both stretching (asymmetrical + symmetrical) and overtone of bending vibrations [44].

Most probably the direct intercalation of DMSO into the interlayer sheets of kaolinite was first achieved by [33]; the rule is that when DMSO molecules are intercalated into the kaolinite layers (which elsewhere has been described as ion 


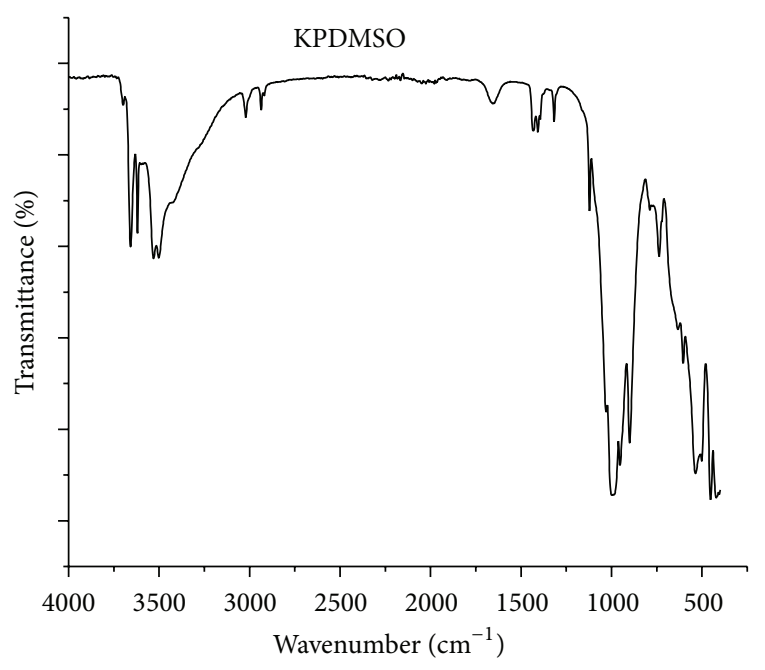

FIgURE 7: ATR-FTIR spectrum of KPDMSO.

substitution or site vacancies at the tetrahedral/octahedral sheets [6]) there would be a noticeable significant changes in the $\mathrm{OH}$ stretching region upon absorption of IR bands. This is clearly seen in Figures 5, 6, and 7, respectively, where the IR absorption bands of original, treated, and DMSO intercalated kaolinite are presented. Fundamentally, the infrared spectrum of the kaolinite-DMSO complex was expected to reveal the presence of alumina in both octahedral and tetrahedral configuration for the intercalated kaolinite. As can be seen the absorptions lies in the near IR region whereby the vibrational frequencies at 3698 to $3619 \mathrm{~cm}^{-1}$ represent the characteristic hydroxyl stretching vibrations of alumina of the kaolinite in the octahedral configuration whereas the bands at $736 \mathrm{~cm}^{-1}$ correspond to the characteristic hydroxyl stretching vibrations of alumina of the kaolinite in the tetrahedral configuration for the $\mathrm{AlO}_{4}$ antisymmetric stretching and that at $633 \mathrm{~cm}^{-1}$ they are attributed to the characteristic hydroxyl stretching vibrations of alumina of the kaolinite in the tetrahedral configuration for the $\mathrm{AlO}_{4}$ symmetric stretching. These predictions agree with $[33,45]$. The vibrations at $3657 \mathrm{~cm}^{-1}$ are attributed to the $\mathrm{OH}$ stretching of the inner surface hydroxyl of the original kaolinite. Furthermore, we had observed that upon DMSO intercalation a new band at $3698 \mathrm{~cm}^{-1}$ was formed in the kaolinite-DMSO complex; this was related to the disappearance of the $3683 \mathrm{~cm}^{-1}$ band frequency of the treated kaolinite. In addition, an increase in wavelength from low to high (although a small shift) has been observed signifying that the intercalation was successful. This was confirmed by the appearance of a series of new bands upon intercalation as seen in Figure 7. The occurrence of infrared bands at 3012 and $2936 \mathrm{~cm}^{-1}$ which is close to the results obtained by [35] revealed the formation of organoclay compound and in this context we refer to the formation of kaolinite-DMSO intermediate nanocomposite. We have in turn ruled out that these bands would, respectively, be representing the $-\mathrm{CH}_{2}$ stretching for both symmetric and asymmetric vibrations.
Moreover, the new sharp two-split peaks at 3530 and $3501 \mathrm{~cm}^{-1}$ correspond to the formation of the moderately hydrogen bonds between some of the inner-surface hydroxyls of the kaolinite layers and the sulfonyl oxygen of the intercalated DMSO molecules; this agrees with Thompson and Cuff's predictions [46]. Similarly, our conclusion also agrees with [47-49] whose works reported IR bands at 3538 and $3502 \mathrm{~cm}^{-1}$. Moreover, the peak at $3657 \mathrm{~cm}^{-1}$ correspond to the inner-surface hydroxyl hydrogen bonded to the $\mathrm{S}=\mathrm{O}$ group as referred to elsewhere [49]. There is also a unique $\mathrm{CH}$ band split into two bands at $1434 \mathrm{~cm}^{-1}$ and $1407 \mathrm{~cm}^{-1}$ and is attributed to the in-plane methyl deformation vibration of DMSO; in point of fact, this is in agreement with [49] who obtained two-split IR bands at 1411 and $1430 \mathrm{~cm}^{-1}$ due to intercalated DMSO methyl deformation.

Basing on the literature surveyed, we have concluded that the distinct intense IR band seen at $1317 \mathrm{~cm}^{-1}$ represents the deformation of the inner surface $\mathrm{OH}$ groups hydrogen bonded to the $\mathrm{S}=\mathrm{O}$ group of the DMSO molecules intercalated into the kaolinite layers and this reveals that only one type of hydrogen bonded inner surface $\mathrm{OH}$ group was formed during DMSO-kaolinite interaction as put forward by [49]. The analysis results also show that there is only one type of water molecules vibrations present; this is evidenced by the appearance of single broad band at $1655 \mathrm{~cm}^{-1}$ which is ascribed to water bending vibrations and that this single water molecule is hydrogen bonded to only one type of DMSO molecule associated with the kaolinite inner-surface $\mathrm{OH}$ groups observed at $1029 \mathrm{~cm}^{-1}$. According to [33], the vibrational assignments at $1121 \mathrm{~cm}^{-1}$ correspond to the in plane Si-O vibrations; at $998 \mathrm{~cm}^{-1}$ and $951 \mathrm{~cm}^{-1}$ represent Al$\mathrm{OH}$ vibrations; at 736, 633, and $603 \mathrm{~cm}^{-1}$ vibrations stand for the gibbsite-like layers of the kaolinite; and, also, bands at 536,501 , and $452 \mathrm{~cm}^{-1}$ correspond to the $\mathrm{Si}-\mathrm{O}-\mathrm{Al}$ skeletal vibrations.

Furthermore, upon introducing methoxy group into the kaolinite layers, several changes were observed in the IR spectrum as compared to the beneficiated and treated kaolinite and KPDMSO-kaolinite. As seen for KPDM in Figure 8, new bands were observed at 3698,3659 , and $3619 \mathrm{~cm}^{-1}$ with similar reasons to ones given for KPDMSO above. However, the band at $3619 \mathrm{~cm}^{-1}$ is shown to be unshifted from the original kaolinite, modified kaolinite, DMSO intercalated kaolinite, and now in the methanol intercalated kaolinite; this is in fact in agreement with $3620 \mathrm{~cm}^{-1}$ wavelength obtained by [45]. The doubly split weak broad band at $3533 \mathrm{~cm}^{-1}$ is ascribed to the externally adsorbed water as suggested by [ 45 , 50]; this band has also been considered as the $\mathrm{OH}$ stretching of methanol molecules and/or of water molecules formed during the esterification reaction of kaolinite inner-surface $\mathrm{OH}$ groups and methanol molecules [51]. The region around 3021 to $2800 \mathrm{~cm}^{-1}$ is marked by the three-split band and is ascribed to the methanol-kaolinite interaction. To be clearer, the $\mathrm{OH}$ stretching bands from alcohol molecules is visualized by band at $3012 \mathrm{~cm}^{-1}$ while at $2800 \mathrm{~cm}^{-1}$ it is attributed to the $\mathrm{C}-\mathrm{H}$ stretching mode of methanol intercalated into the interlayer spaces of kaolinite sheets. The band at $2935 \mathrm{~cm}^{-1}$ 
refers to the $\mathrm{C}-\mathrm{H}$ stretching region which confirms the presence of $-\mathrm{OCH}_{3}$ groups in the kaolinite interlayer spaces $[50,51]$. A similar observation was made by [52] in that bands at $3021 \mathrm{~cm}^{-1}$ and $2935 \mathrm{~cm}^{-1}$ represent the $\mathrm{C}-\mathrm{H}$ stretching mode of methanol; according to him, these vibrations are attributed to the $\mathrm{CH}_{3}$ out-phase and in-phase stretches of the methanol, respectively, which in turn act as an evidence for the grafting reaction of methoxy group in the kaolinite interlayer space as noted by [45]. Correspondingly, the bands at $1122 \mathrm{~cm}^{-1}$ are ascribed to the $\mathrm{C}-\mathrm{O}$ stretching deformation in methanol molecules; this agrees with the C-O stretching deformation of $1123 \mathrm{~cm}^{-1}$ in methanol-kaolinite obtained by [45] while the new band recorded at $1003 \mathrm{~cm}^{-1}$ which also agrees with $1004 \mathrm{~cm}^{-1}$ obtained by [45] represents the lattice $\mathrm{Si}-\mathrm{O}$ vibration bands due to methanol-kaolinite intercalation and it corresponds to a shift from $1113 \mathrm{~cm}^{-1}$ of the modified kaolinite. The observed low intensity bands at $957 \mathrm{~cm}^{-1}$ correspond to the $\mathrm{Al}-\mathrm{OH}$ deformation whereas the band seen at $902 \mathrm{~cm}^{-1}$ is ascribed to the $\mathrm{Al}-\mathrm{OH}$ in-plane bending vibration of the inner hydroxyl of kaolinite and this corresponds to a shift from $899 \mathrm{~cm}^{-1}$ of KPDMSO and $910 \mathrm{~cm}^{-1}$ of the modified kaolinite and $909 \mathrm{~cm}^{-1}$ of the beneficiated and treated (NaKP) kaolinite mineral. We have attributed the new kaolinite band at 789, 740,675,635, and $427 \mathrm{~cm}^{-1}$ in contrast to the beneficiated and treated $(\mathrm{NaKP})$ kaolinite to the modifications of the bands related to the $\mathrm{Si}-\mathrm{O}$ and $\mathrm{Al}-\mathrm{OH}$ vibrations resulting from the perturbation of the kaolinite structure due to grafting of the methanol molecule; this again is in agreement with some of the results obtained elsewhere [45]. Noticeably, the IR spectra of both KPDMSO and KPDM revealed that DMSO molecules were successfully replaced by methanol molecules. This was evidenced by either a shift of characteristic bands or disappearance/appearance of new bands between the two. Similarly, there are clear substantial changes in the intensity of IR spectra in the $\mathrm{OH}$ region due to intercalation of DMSO and methoxy and the grafting of methoxy into the interlayer spaces of kaolinite sheets. This implies that there was a significant alteration in the local environment of inner-surface hydroxyl groups when DMSO molecules were replaced with methanol molecules during intercalation and grafting process. In fact, the presence of methoxy groups into the kaolinite layers is revealed by the significant decrease in the intensity of band representing interlamellar Al-OH of the silicate sheets at $957 \mathrm{~cm}^{-1}$ in the KPDM as compared to that of $953 \mathrm{~cm}^{-1}$ in the KPDMSO; this phenomenon is ascribed to the formation of Al-O-C bonds resulting from the grafting of methoxy groups into the kaolinite interlayer spaces, a fact that has been put forward and hence agrees with the findings obtained by [51].

According to [49], urea and kaolinite sheets interact via hydrogen bonds both through the $\mathrm{NH}_{2}$ groups connected to the tetrahedral oxygens and through hydroxyl groups of the ions (located in the coordination sphere) connected to the carbonyl groups of urea. As seen, for the KPDMSO and KPDM (Figures 7 and 8), the position of the $\mathrm{OH}$ - bands was similar at 3698,3657 , and $953 / 957 \mathrm{~cm}^{-1}$; however, for the KPDMU (Figure 9), there is a complete disappearance of the outer hydroxyl stretching vibrations while the inner

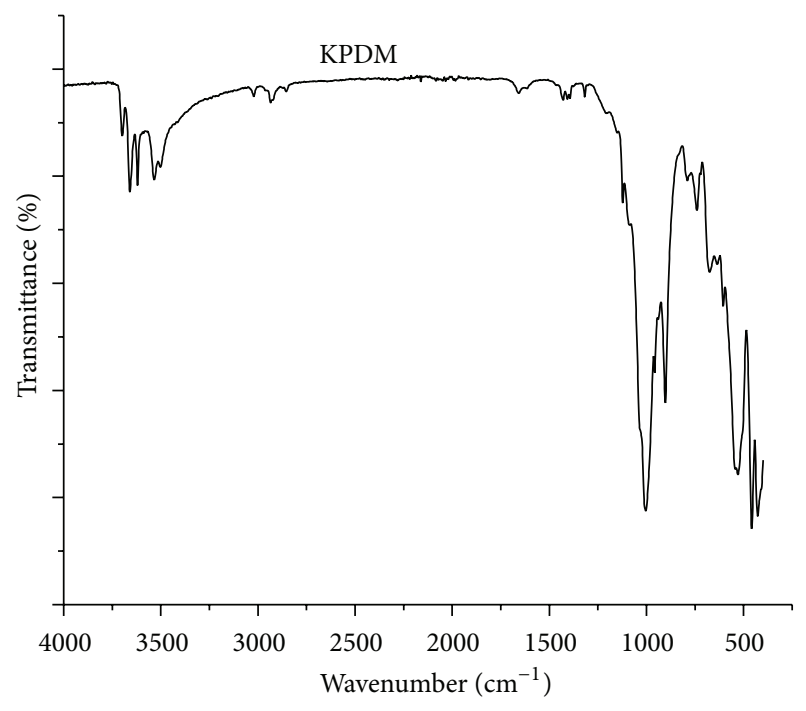

FIgURE 8: ATR-FTIR spectrum of KPDM.

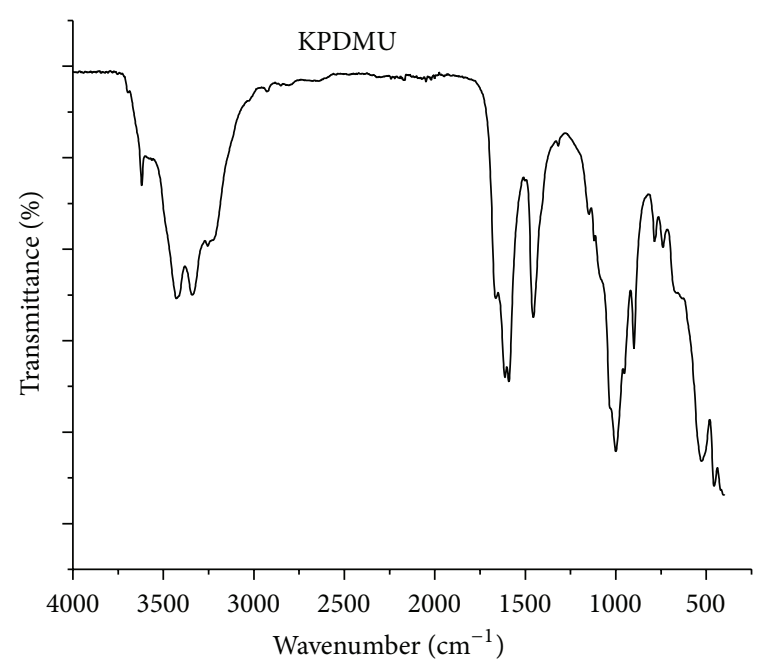

FIgURE 9: ATR-FTIR spectrum of KPDMU.

hydroxyl stretching vibrations occurring at $3619 \mathrm{~cm}^{-1}$ remained. Based on the predictions established by [52], the vibrations occurring at $3427 \mathrm{~cm}^{-1}$ could be attributed to the out-of-phase vibrations of the $\mathrm{N}-\mathrm{H}$ stretch in the tetragonal urea while at $3340 \mathrm{~cm}^{-1}$ they could be assigned to the in-phase vibrations of the $\mathrm{N}-\mathrm{H}$ stretch [49] and this agrees with the bands at 3420,3436 , and $3333 \mathrm{~cm}^{-1}$ obtained by [53], while, on the other hand, the free $\mathrm{C}=\mathrm{O}$ stretch and some free bending $\mathrm{NH}_{2}$ motions [54] due to urea are ascribed to the $1612 \mathrm{~cm}^{-1}$ vibrations; this is in agreement with $[54,55]$. In addition, the vibrations observed at $1590 \mathrm{~cm}^{-1}$ represent the $\mathrm{H}-\mathrm{N}-\mathrm{C}+\mathrm{C}-\mathrm{N}$ stretch and the in-phase $\mathrm{CH}_{3}$ bend of urea occurs at $1455 \mathrm{~cm}^{-1}$ vibration. In reference to known computer simulations the possible orientation of urea in the kaolinite-urea complex described that urea molecules point towards the silica sheet such that the hydrogen bonding is formed between the $\mathrm{N}-\mathrm{H}$ group and the siloxane surface 


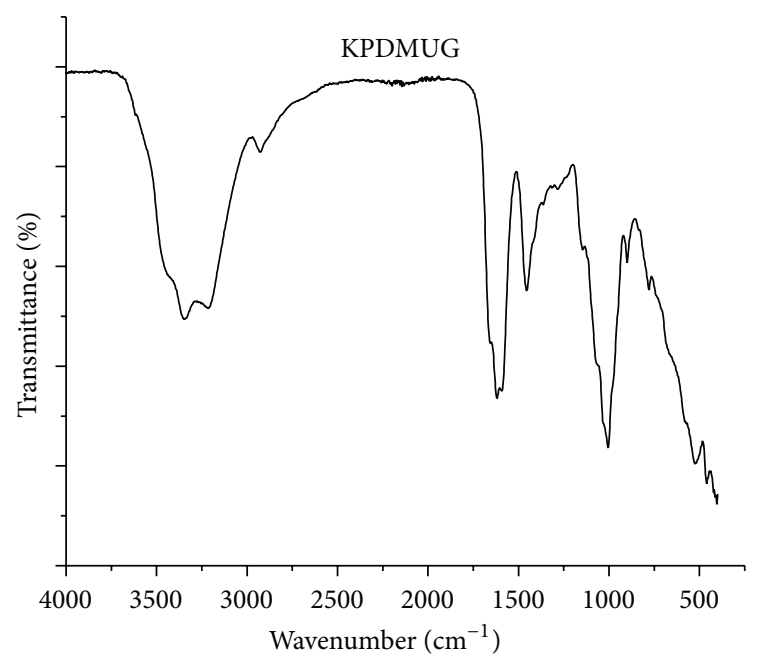

Figure 10: ATR-FTIR spectrum of KPDMUG.

while conjugation between the $\mathrm{C}=\mathrm{O}$ and $\mathrm{N}-\mathrm{H}$ groups no longer exists; in so speaking the free $\mathrm{C}=\mathrm{O}$ vibration bands in the IR spectra were expected to be seen $[49,56]$. In many cases, the $\mathrm{C}=\mathrm{O}$ stretching vibrations in saturated aliphatic aldehydes, ketones, and acids have frequencies in the range $1740-1700 \mathrm{~cm}^{-1}$ [54], which is higher than the observed vibrations for the KPDMU and the reason as pointed out by [54] is attributed to the existence of resonance structures caused by the presence of the free $\mathrm{C}=\mathrm{O}$ molecules which interact with $\mathrm{NH}_{2}$, a mechanism which has been described elsewhere [54]. Precisely, the IR bands seen at $1455 \mathrm{~cm}^{-1}$ represent the asymmetric or scissoring $\mathrm{C}-\mathrm{N}$ vibrations while those occurring at $1000 \mathrm{~cm}^{-1}$ were ascribed to the C-N symmetric modes and this is in agreement with 1465 and $1000 \mathrm{~cm}^{-1}$ by [54] and 1468 and $1010 \mathrm{~cm}^{-1}$ by [55]. The bands occurring at $1149 \mathrm{~cm}^{-1}$ represent the wagging or rocking $\mathrm{N}-\mathrm{H}$ vibrations due to urea intercalated into the kaolinite layers; again this agrees with $\mathrm{N}-\mathrm{H}$ vibrations at $1155 \mathrm{~cm}^{-1}$ obtained by [54]. According to the predictions made by $[55,57]$, the vibrations occurring at $786 \mathrm{~cm}^{-1}$ were ascribed to mutual $\mathrm{N}-\mathrm{H}$ and $\mathrm{CO}$ out-of-plane wagging vibrations or in other words it is called the skeletal out-of-phase bending frequency equally attributable to larger deformational force constant, resulting from the decrease in the N-N distance of tetragonal urea [53]. Finally, for the KPDMU, the infrared bands occurring at $739 \mathrm{~cm}^{-1}$ represent the characteristic hydroxyl stretching vibrations of alumina of the kaolinite in a tetrahedral configuration for the $\mathrm{AlO}_{4}$ antisymmetric stretching while the $\mathrm{SiOAl}$ skeletal vibrations are observed at $527 \mathrm{~cm}^{-1}$.

Above that, unique changes were observed when gum arabic was used to encapsulate the urea-kaolinite intercalation compound to form the targeted nanocomposite KPDMUG. As can be seen in Figure 10, there is a complete disappearance of kaolinite peaks at 3683, 3650, and $3618 \mathrm{~cm}^{-1}$. Besides, a unique observation was made on the vibrations occurring at $3618 \mathrm{~cm}^{-1}$ in that (i) the peak remained unaffected in the beneficiated and raw kaolinite as well as in the associated intercalation compounds KPDMSO, KPDM, and KPDMU. That is to say, despite all the modifications made on the kaolinite, that peak position remained unaltered; (ii) when these three kaolinite intercalations compounds were encapsulated with gum arabic biopolymer to form KPDMUG the peak got disappeared completely. This implies that the gum arabic encapsulation reaction was effective and successful. Noticeably, the out-phase vibration of the KPDMU at $3427 \mathrm{~cm}^{-1}$ has disappeared altogether. The band at $3340 \mathrm{~cm}^{-1}$ for KPDMU was raised to $3346 \mathrm{~cm}^{-1}$ in the KPDMUG. Two completely new bands appeared at 3212 and $2924 \mathrm{~cm}^{-1}$ with unique positioning and that is to say, there is a shift of the position $3427 \mathrm{~cm}^{-1}$ of KPDMU to $3346 \mathrm{~cm}^{-1}$ of KPDMUG and $3340 \mathrm{~cm}^{-1}$ of KPDMU to $3213 \mathrm{~cm}^{-1}$ of the KPDMUG although the peak shape was seen to change from narrow-sharp to broad for the KPDMUG. In such a phenomenon as pointed out by [53] that, upon crosslinking KPDMU with gum Arabic, the out-phase vibration shifted from $3427 \mathrm{~cm}^{-1}$ of KPDMU to $3346 \mathrm{~cm}^{-1}$ of KPDMUG while the in-phase vibration shifted from $3340 \mathrm{~cm}^{-1}$ of KPDMU to $3213 \mathrm{~cm}^{-1}$ of the KPDMUG. This phenomenon indicated that, upon crosslinking with gum arabic, urea's unit cell was going from tetragonal to hexagonal shape as revealed from the spectra changes in the N-H stretching region of both KPDMU and KPDMUG. According to the assumptions made by [53], the tetragonal urea has its structure characterized by shorter hydrogen bonds which in fact made us assume that there will be lengthening of $\mathrm{H}$-bonds in the hexagonal type. That is to say, during the formation of complex crosslinked urea-kaolinite structure, hydrogen bonding caused a change in orientation from more favorable tetragonal structure to a less favorable hexagonal structure which in turn reduced the stability of the latter as contrarily given by [53].

Our prediction on the peak positioning after critical review in [58-60] is that the band seen at $3346 \mathrm{~cm}^{-1}$ represents the $\mathrm{N}-\mathrm{H}$ stretch of urea while that in $3213 \mathrm{~cm}^{-1}$ corresponds to the $\mathrm{O}-\mathrm{H}$ stretching vibrations which signifies that there is a hydrogen bonded hydroxyl group between the polymer and the intercalated nanocomposite. Precisely, this absorption band shows that the $\mathrm{O}-\mathrm{H}$ bond was formed in the bonding of the intercalated nanocomposite and the crosslinking polymeric membrane [58]. A general observation in our view is that the strong broad band at 2924 and $1619 \mathrm{~cm}^{-1}$ is typical for carbohydrates which in our case refers to gum arabic grafted onto the substrate [59]. In a narrower view, the vibrations at $2924 \mathrm{~cm}^{-1}$ were ascribed to the C-H stretching; this deviates a little bit from $2933 \mathrm{~cm}^{-1}$ obtained by [60]. Based on the fact that this band emerged as a new shoulder upon crosslinking with gum arabic on the KPDMU, our conclusion has therefore been that it represents the symmetric stretching of both $\mathrm{CH}_{2}$ and $\mathrm{CH}$ groups which in turn proves the existence of grafting of gum arabic on the nanocomposite KPDMU [60]. The strong-high intensity peak at $1619 \mathrm{~cm}^{-1}$ corresponds to the $\mathrm{COO}$ asymmetric stretching (i.e., $v \mathrm{C}=\mathrm{O} ; v \mathrm{C}-\mathrm{O}$ ) resulting from the interaction between gum arabic and the urea-kaolinite nanocomposite. This can be equally compared with $1610 \mathrm{~cm}^{-1}$ obtained by [60]. Based on the observations made before, we have concluded that 


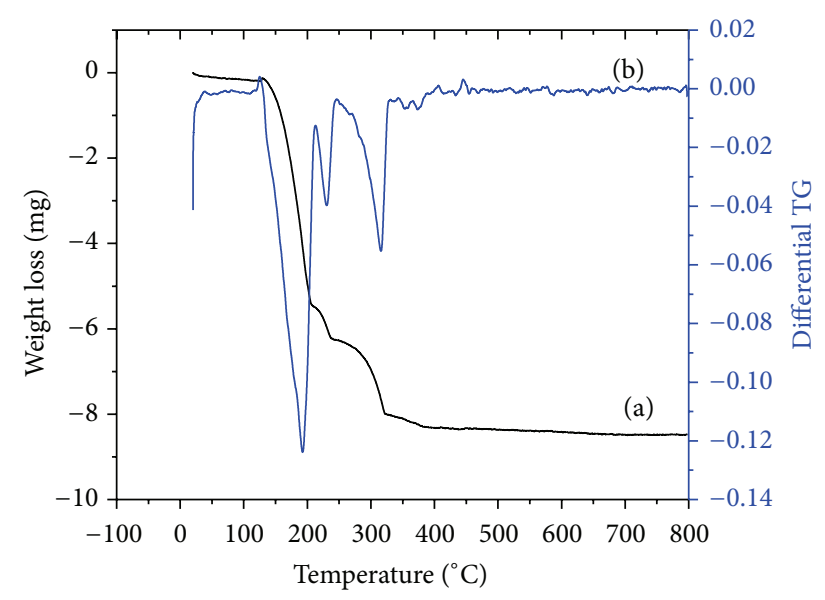

FIgURE 11: (a) TGA thermograms of urea. (b) Differential plot of urea fertilizer.

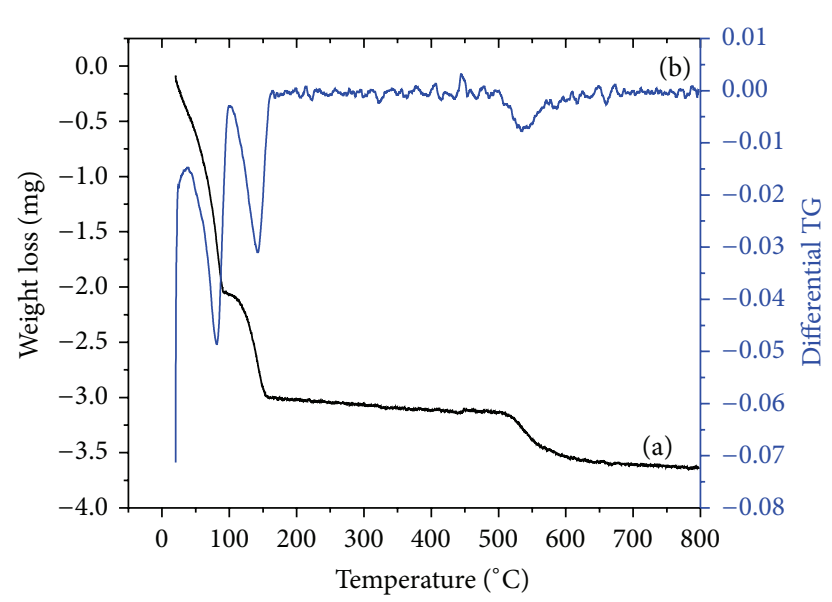

FIGURE 12: (a) TGA thermograms of KPDMSO. (b) Differential plot of KPDMSO.

the vibrations observed at $1455 \mathrm{~cm}^{-1}$ were ascribed to the in phase bending of urea. A close analysis of the frequencies seen at $1004 \mathrm{~cm}^{-1}$ made us to ascribe us to the $\mathrm{C}-\mathrm{N}$ vibrations. In addition, the infrared band occurring at $779 \mathrm{~cm}^{-1}$ represents the characteristic hydroxyl stretching vibrations of alumina of the kaolinite in a tetrahedral configuration for the $\mathrm{AlO}_{4}$ antisymmetric stretching while the $\mathrm{SiOAl}$ skeletal vibrations are observed at $525 \mathrm{~cm}^{-1}$.

3.8. Thermogravimetric Analysis. TG-DTG analysis was employed in investigating thermal degradation and stability of the samples under $\mathrm{N}_{2}$ atmosphere. Relative to the TG thermograms for pure urea fertilizer (Figure 11), DMSO intercalated kaolinite (Figure 12) exhibited three degradation phases: the first was observed around $48-98^{\circ} \mathrm{C}$ attributed to the evaporation of externally adsorbed water on the kaolinite platelets, and this is related to $43^{\circ} \mathrm{C}$ obtained by [45]. The second degradation was observed around $120-170^{\circ} \mathrm{C}$ corresponding to the removal and decomposition of DMSO,

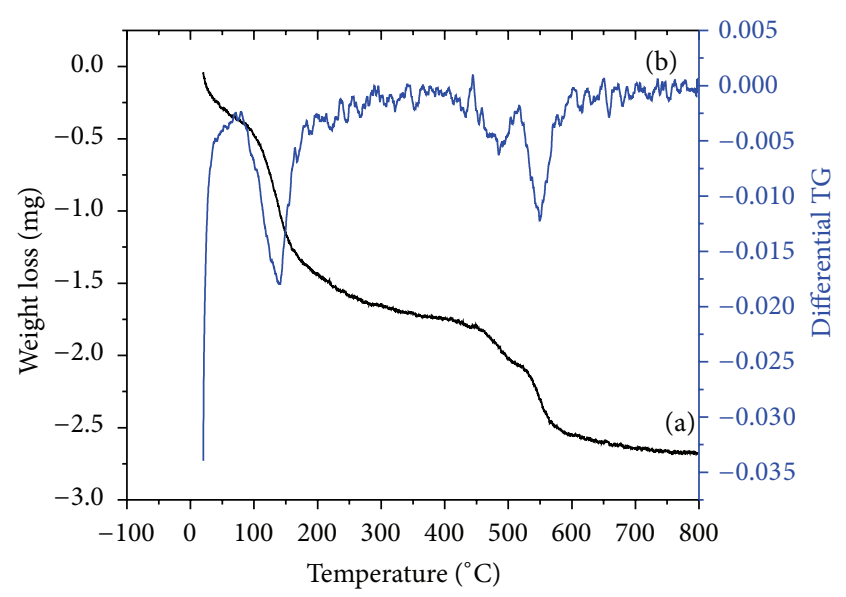

FIGURE 13: (a) TGA thermograms of KPDM. (b) Differential plot of KPDM.



FIGURE 14: (a) TGA thermograms of NaKP. (b) Differential plot of $\mathrm{NaKP}$.

whereas the third phase was observed at around $520-575^{\circ} \mathrm{C}$ which corresponds to the dehydroxylation of kaolinite sheets. Considerably, in average, these results are, respectively, comparable to 154 and $485^{\circ} \mathrm{C}$ obtained by [61] and, also, $181^{\circ} \mathrm{C}$ and $514^{\circ} \mathrm{C}$ obtained by [45]. On the other hand, methanol intercalated kaolinite is associated with two decomposition stages (Figure 13): the first which is comparably narrow was observed around $75-250^{\circ} \mathrm{C}$ corresponding to the removal of water moisture adsorbed on the sample as well as externally adsorbed methanol molecules, and this was relatively lower than $350^{\circ} \mathrm{C}$ obtained by [45]. The second degradation stage which is comparatively wider was observed at around 450$600^{\circ} \mathrm{C}$ corresponding to the decomposition of methanolkaolinite intercalated compound and this observation reveals that methanol intercalated compound is highly hygroscopic such that the high amount of adsorbed water was completely removed at $250^{\circ} \mathrm{C}$. According to [62], kaolins undergo dehydroxylation transformation within $400-700^{\circ} \mathrm{C}$ temperature range; however, the maximum dehydroxylation of kaolinite in the modified kaolinite (NaKP) was observed (Figure 14) at 


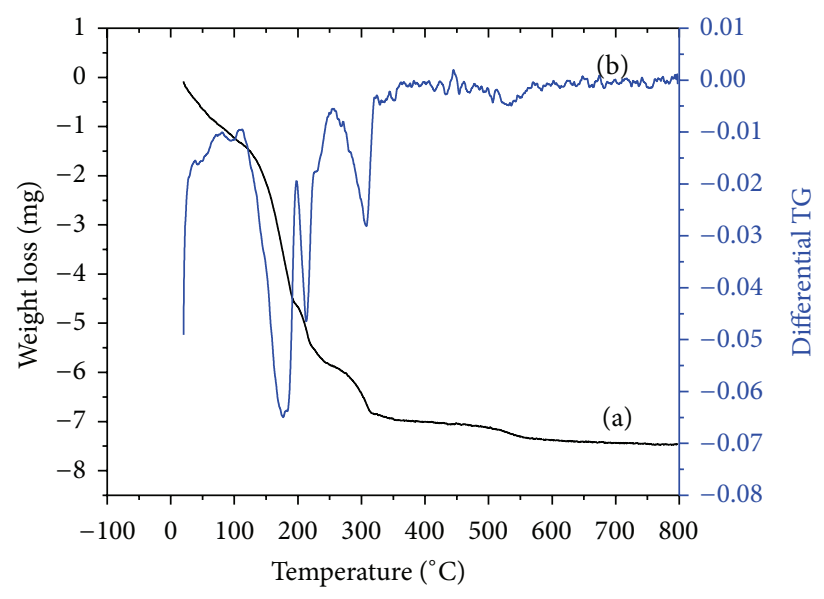

FIGURE 15: (a) TGA thermograms of KPDMU. (b) Differential plot of KPDMU.

$575^{\circ} \mathrm{C}$; therefore, a close look at the dehydroxylation transformation of $450-600^{\circ} \mathrm{C}$ for methanol intercalated kaolinite prepared would reveal an increased thermal stability. Furthermore, slight but significant changes in the thermal decomposition behavior with three degradation stages were observed when urea replaced methanol in the kaolinite interlayer spaces to form KPDMU (Figure 15). The first weight loss was observed at approximately $100-125^{\circ} \mathrm{C}$ corresponding to the following: (i) the loss of nonconstitutional water, (ii) removal of interlayer water, (iii) elimination of water coordinated to exchangeable cations or structural water as mentioned in [63], and (iv) degradation of urea; this discloses the fact that the release properties of our engineered urea CRF formulation would work best at that temperature range. Based on the findings obtained by [64], urea loss at about $140-250^{\circ} \mathrm{C}$ is caused by both (i) its own vaporization and (ii) degradation to its complementary form known as biuret $\left[\mathrm{NH}(\mathrm{CO})_{2}\left(\mathrm{NH}_{2}\right)_{2}\right]$. The second weight loss was observed at about $225-350^{\circ} \mathrm{C}$ attributed to (i) the continuous sublimation of urea and (ii) decomposition or self-condensation of biuret $\left[\mathrm{NH}(\mathrm{CO})_{2}\left(\mathrm{NH}_{2}\right)_{2}\right]$ to more complex decomposition product to the completion of vaporization and degradation reaction [64]. The third weight loss was observed at around $500-575^{\circ} \mathrm{C}$ and was ascribed to the dehydroxylation of kaolinite a phenomena constituted by the decomposition of urea-kaolinite intercalated compound as well as elimination of structural hydroxyl and organic matter $[45,62,63]$. Comparatively, the thermal stability of methanol intercalated kaolinite and urea intercalated kaolinite increase in the inverse order.

Finally, the TG thermogram for the KPDMUG nanocomposite is associated with two degradation stages: the first was observed at approximately $48-425^{\circ} \mathrm{C}$ ascribed to the moisture evaporation, decomposition of the gum arabic biopolymer, and the elimination of interlayer moisture and water coordinated in the exchangeable cations as named by [63]. In fact, decomposition of gum arabic has been found to be in a range between 72 and $318^{\circ} \mathrm{C}[65]$ which signifies that temperature below that and above that range is due to moisture evaporation as well as elimination of interlayer



FIGURE 16: (a) TGA thermograms of KPDMUG. (b) Differential plot of KPDMUG.

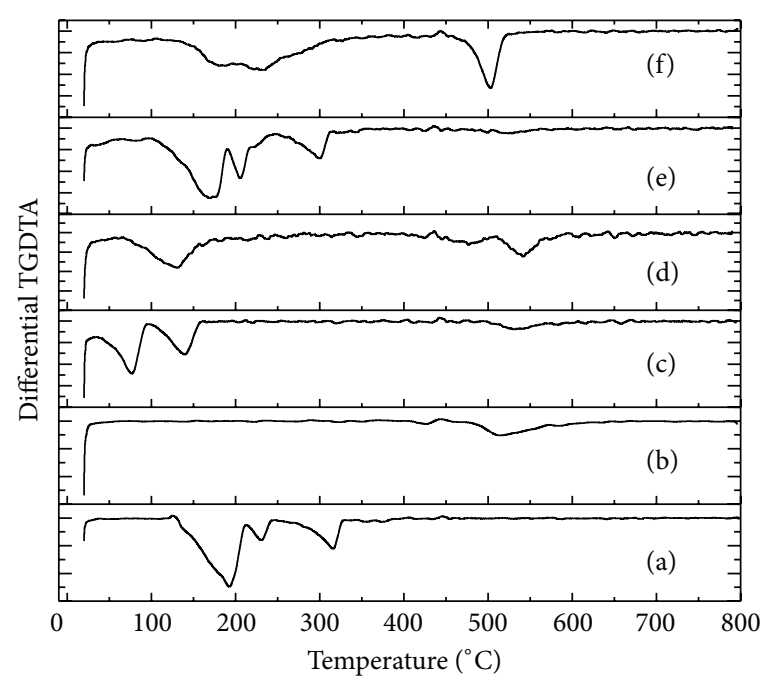

FIGURE 17: Differential thermograms.

moisture and coordinated water, respectively. The second stage occurring at about $475-550^{\circ} \mathrm{C}$ corresponds to the dehydroxylation of kaolinite. In this work, the first thermal degradation phase of the nanocomposite is the most titillating and significant since it reflects the objective of our study aimed at designing urea based CRF formulation via kaolinite intercalation reactions followed by encapsulation. As seen in Figure 16, the first degradation temperature with maxima at $425^{\circ} \mathrm{C}$ ascribed to urea reveals an increased thermal stability of the nanocomposite (KPDMUG) relative to the urea intercalated kaolinite (KPGMU) whose first thermal degradation temperature was noted to be at $205^{\circ} \mathrm{C}$ maxima.

In addition to that, the derivative thermogravimetric analysis (DTG) as seen in (Figure 17) provided the information regarding the thermal stability behavior of the prepared materials. KPDMSO and KPDM are dominated by decomposition of nonconstitutional water and kaolinite degradation; when compared to the DTG curve of NaKP, KPDMSO has an increased thermal stability by $10^{\circ} \mathrm{C}(520$ for NaKP vis-à-vis 
530 for KPDMSO), whereas KPDM has an increased thermal stability by $30^{\circ} \mathrm{C}$ ( 520 for NaKP vis-à-vis 550 for KPDM) and this portrays a substantial increase in melting temperature of the intercalated compounds as related to the modified kaolinite NaKP. On the contrary, the DTG curve of urea intercalated kaolinite and the nanocomposite is characterized by the urea degradation, a phenomenon which was also noted (although in a different setting) by [63] which in our case is marked by temperature regimes of $199^{\circ} \mathrm{C}, 226^{\circ} \mathrm{C}$, and $320^{\circ} \mathrm{C}$ for pure urea; $175^{\circ} \mathrm{C}, 215^{\circ} \mathrm{C}$, and $302^{\circ} \mathrm{C}$ for urea intercalated kaolinite (KPDMUG), and $180^{\circ} \mathrm{C}, 240^{\circ} \mathrm{C}$, and $510^{\circ} \mathrm{C}$ for nanocomposite (KPDMUG). The presence of some free kaolinite residues not crosslinked was also noted and was revealed by the high $510^{\circ} \mathrm{C}$ decomposition temperature observed only in the KPDMUG but absent in the pure urea and KPDMU.

3.9. Urea Release Profiles. The release of urea from pure urea, KPDM, and KPDMUG as a function of time (in 5-hour intervals) was done by first weighing the amount of sample and then introducing the sample into the known volume of water contained in the dialysis bags. The system was shaken continually throughout the release trials. Measurements were taken after every 5 -hour interval by simply drawing the solution from the dialysis membranes for analysis. Spectrophotometric determination of the amount of urea in water with hypochlorite and phenol technique was done thereafter. The method was adopted from [66] involving 8 steps which involves transferring a $20.0 \mathrm{~mL}$ aliquot of sample, which should be colorless, free from solid matter, and at room temperature to a $25 \mathrm{~mL}$ volumetric flask containing a microstirring magnet. Sample cavitation was barred through rapid addition because the microbubbles contribute to the blank signal; then $3.0 \mathrm{~mL}$ of distilled water was added and stirred vigorously followed by the addition of $0.30 \mathrm{~mL}$ of $\mathrm{NaOCl}$ reagent. After 5 seconds, $0.50 \mathrm{~mL} \mathrm{NaOBr}$ was added with one hand whereas $(0.30+X) \mathrm{mL}$ of $\mathrm{HCl}$ reagent was added with the other hand after 2 more seconds ( $X$ " is the volume in $\mathrm{mL}$ of $\mathrm{HCl}$ reagent required to titrate $0.50 \mathrm{~mL}$ of $\mathrm{NaOBr}$ reagent to $\mathrm{pH}$ 7.0). Furthermore, after 20 seconds, $0.50 \mathrm{~mL}$ of $\mathrm{H}_{3} \mathrm{BO}_{3}$ buffer reagent was added with one hand followed with addition of $0.30 \mathrm{~mL}$ ethanolic phenol reagent after 2 more seconds with the other hand and stirred for 20 more seconds. After these 20 seconds, the absorbency of the sample solution at $454 \mathrm{~nm}$ was compared against distilled water. The blank sample procedures may be found elsewhere [66]. Calculations were then done to determine the concentration of urea by multiplying the difference between the blank and the general sample absorbencies by the difference between the general and standard sample absorbencies and divide by three twentieths the urea-N concentration of the added standard solution. The reader is recommended to view the detailed procedure and the mechanisms associated with the original author of this method [66].

Besides, the rate of urea release as a function of time for a period of 150 hours was then investigated and summarized in Figure 18. As can be seen, upon arduous dissolution test performed, $100 \%$ of the pure urea was released in just the first five hours of the first attempt to draw the aliquot, a

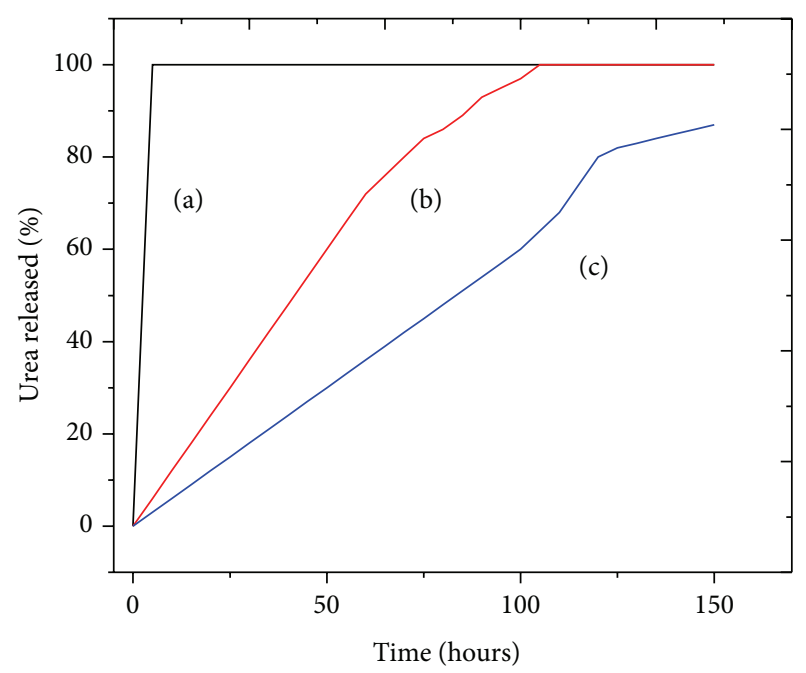

FIGURE 18: Release rate of (a) pure urea, (b) KPDMU, and (c) KPDMUG as a function of time at $\mathrm{pH} 7$ and room temperature.

result which was expected due to volatility of urea fertilizer associated with up to 60 to $70 \%$ loss in few minutes of the nitrogen being applied to the field [2] such that its utilization efficiency or plant uptake of urea is generally below $50 \%$ [1]. For the urea intercalated kaolinite nanocomposite (KPDMU) the observation made was that $100 \%$ of the intercalated urea was released within 97 hours, thereby unveiling the fact that Pugu kaolinite can retain urea and so can be used as a natural excipient for the preparation of CRF formulations. This observation indicated that urea adsorption and its subsequent intercalation into the kaolinite interlayer spaces was successful such that for its dissolution to take place an extended period of time was needed to induce its release mechanism. Furthermore, the ability of gum arabic biopolymer to retard urea dissolution was also noticed by its ability to retard urea release for a period of more than 150 hours. As can be seen, only $87 \%$ of the encapsulated urea contained into the kaolinite sheets was released after 150 hours. Such appealing results confirm our hypothesis that Pugu kaolinite layers can be expanded to accommodate molecular moieties; that is to say, it can be used to design CRF formulations based on urea fertilizer. As it was pointed out elsewhere [63] (a fact with which we also agree) that "in conventional application, the materials would be exposed to low water contents, and one can expect a better retention effect by the nanocomposites." That is to say, the period of urea release from both urea intercalated kaolinite nanocomposite and encapsulated urea nanocomposite is expected to be more than these reported values done in the harsh laboratory settings.

\section{Conclusion}

In Tanzania, nitrogenous fertilizers have been used for years by virtue of their high nitrogen content to supplement nitrogen to crop plants. However for urea despite having high nitrogen content of about $46 \%$, it has been associated 
with approximately 60 to $70 \%$ loss of the nitrogen being applied because of ammonia produced through hydrolysis of urea by soil urease, a problem which could be minimized by inhibiting soil urease through encapsulation with synthetic or biopolymers as well as intercalation with nanoclays. In this paper we have described the amendments of urea fertilizer through intercalation into the kaolinite interlayer spaces and then encapsulating the intercalation compound with gum arabic biopolymer for the purpose of preparing urea control release fertilizer which in turn will minimize its volatility as well as improve its utilization efficiency (FUE) by plants and also minimize the losses, thereby reducing repeated fertilization expenditure per season and maximize crop yields. The entire experimental setup involved takes in the sampling of raw kaolinite from Pugu hills, Tanzania, beneficiation of the raw kaolinite, activation of kaolinite layers, preparation of intermediate intercalation compounds, and intercalation of urea fertilizer into the kaolinite layers by replacement reaction. Similarly, the intercalated urea fertilizer was subsequently encapsulated by using gum arabic biopolymer. The nanomaterials synthesized were characterized by using several techniques including ATR-FTIR, XRD, SEM, XRF, TGDTG, and particle size analysis via Scherrer equation along with distribution of particles through the application of Andreasen pipette sedimentation method. Our effective beneficiation process was able to minimize nonclay portion from $39.58 \%$ of the raw Pugu kaolinite to $0.36 \%$ of the beneficiated Pugu kaolinite as well as increasing the clay portion from $60.42 \%$ to $99.64 \%$ of raw and beneficiated kaolinite, respectively. The morphology of the samples was observed to change from thick compact overlapping euhedral pseudohexagonal platelets to irregular booklets which then changed to vermiform morphology and dispersed euhedral pseudohexagonal platelets coexisting with blocky-vermicular booklets. The unique brain-form agglomeration and later poor roundish particles organized in mat morphology were observed. The particle sizes of the prepared nanocomposites range from $14.55 \mathrm{~nm}$ to $92.46 \mathrm{~nm}$ whereas the indexing procedures revealed the existence of FCC Bravais lattice for the kaolinite under study. The X-ray mineralogy tests indicated the major phase in the Pugu kaolin under study after beneficiation to be kaolinite subordinated with illite. The intercalation ratios were found to be in the order of $\mathrm{KPDM}>\mathrm{KPDMSO}>\mathrm{KPDMU}$ while the TGDTG thermograms showed that the nanocomposites prepared were capable of decomposing starting from evaporations at $48^{\circ} \mathrm{C}$ to $600^{\circ} \mathrm{C}$ for the dehydroxylation of kaolinite layers. Release profiles were established in a period of 150 hours where the release rates were found to be $100 \%$ in the first 5 hours of trials, $100 \%$ in the period of 97 hours, and $87 \%$ in the period of 150 hours for pure urea, urea intercalated kaolinite nanocomposite, and the encapsulated nanocomposite, respectively.

\section{Conflict of Interests}

The authors declare that there is no conflict of interests regarding the publication of this paper.

\section{Acknowledgments}

The authors would like to thank Miss Niconia Amos Bura and the Institute of Adult Education, Tanzania, for their technical support in the preparation of this paper.

\section{References}

[1] M. Liu, R. Liang, F. Zhan, Z. Liu, and A. Niu, "Preparation of superabsorbent slow release nitrogen fertilizer by inverse suspension polymerization," Polymer International, vol. 56, no. 6, pp. 729-737, 2007.

[2] A. Meybeck and V. Gitz, Greening the Economy with ClimateSmart Agriculture Food, FAO, Hanoi, Vietnam, 2012.

[3] M. N. Court, R. C. Stephen, and J. S. Waid, "Toxicity as a cause of the inefficiency of urea as a fertilizer," Journal of Soil Science, vol. 15, no. 1, pp. 49-65, 1964.

[4] J. M. Bremner and M. J. Krogmeier, "Elimination of the adverse effects of urea fertilizer on seed germination, seedling growth, and early plant growth in soil," Proceedings of the National Academy of Sciences, vol. 85, no. 13, pp. 4601-4604, 1988.

[5] A. Shaviv, "Advances in controlled-release fertilizers," Advances in Agronomy, vol. 71, pp. 1-49, 2001.

[6] S. I. Sempeho, H. T. Kim, E. Mubofu, and A. Hilonga, "Meticulous overview on the controlled release fertilizers," Advances in Chemistry, vol. 2014, Article ID 363071, 16 pages, 2014.

[7] U. Shavit, A. Shaviv, G. Shalit, and D. Zaslavsky, "Release characteristics of a new controlled release fertilizer," Journal of Controlled Release, vol. 43, no. 2-3, pp. 131-138, 1997.

[8] K. M. England, D. M. Camberato, and R. G. Lopez, Commercial Greenhouse and Nursery Production: Water-Soluble and Controlled-Release Fertilization, 2014, https://www.extension .purdue.edu/extmedia/HO/HO-251-W.pdf.

[9] K. G. Satyanarayana and F. Wypych, Clay Surfaces: Fundamentals and Applications, Academic Press, 2004.

[10] E. Cnenrns, "Clays and Clay Minerals," 2015, http://www.sgtk .ch/rkuendig/dokumente/FS10_Clay_handout.pdf.

[11] S. Hillier, "Clay mineralogy", in Encyclopaedia of Sediments and Sedimentary Rocks, G. V. Middleton, M. J. Church, M. Coniglio, L. A. Hardie, and F. J. Longstaffe, Eds., pp. 139-142, Kluwer Academic Publishers, Dordrecht, The Netherlands, 2003.

[12] C. E. Weaver, "The distribution and identification of mixedlayer clay in sedimentary rocks," American Mineralogist, vol. 141, pp. 202-221, 1956.

[13] S. M. Auerbach, K. A. Carrado, and P. K. Dutta, Handbook of Layered Materials, CRC Press, New York, NY, USA, 2004.

[14] J. T. Kloprogge, "Handbook of layered materials: edited by Scott M. Auerbach, Kathleen A. Carrado and Prabir K. Dutta. Marcel Dekker Inc, New York, Basel, 2004, 646 pp. [ISBN 0-8247-53496]. Price \$195," Clays and Clay Minerals, vol. 52, no. 6, pp. 795797, 2004.

[15] A. J. Jacobson and L. F. Nazar, Intercalation Chemistry. Encyclopedia of Inorganic Chemistry, John Wiley \& Sons, 2006.

[16] S. I. Sempeho, E. H. J. Lugwisha, and L. D. Akwilapo, Suitability of kaolin and quartz from Pugu and feldspar from Morogoro as raw materials for the production of dental porcelain [M.S. thesis], University of Dar es Salaam, 2012.

[17] T. Al-Ani and O. Sarapaa, "Clay and clay mineralogy: physical-chemical properties and industrial uses," Tech. Rep. M19/3232/2008/41, Geologian Tutkuskeskus, 2008. 
[18] B. Chen, J. R. G. Evans, H. C. Greenwell et al., "A critical appraisal of polymer-clay nanocomposites," Chemical Society Reviews, vol. 37, no. 3, pp. 568-594, 2008.

[19] S. I. Sempeho, H. J. L. Esther, and D. A. Leonard, Suitability of kaolin and quartz from Pugu and feldspar from Morogoro as raw materials for the production of dental porcelain [M.S. thesis], University of Dar es Salaam, Dar es Salaam, Tanzania, 2012.

[20] N. J. Saikia, D. J. Bharali, P. Sengupta et al., "Characterization, beneficiation and utilization of a kaolinite clay from Assam, India," Applied Clay Science, vol. 24, no. 1-2, pp. 93-103, 2003.

[21] A. Weiss, W. Thielepape, G. Going, W. Ritter, and H. Schaer, "Kaolinit-Enlager Ungsver bind Ungen," in Proceedings of the International Clay Conference, vol. 1, pp. 287-305, Stockholm, Sweden, August 1963.

[22] C. J. Yan, J. Y. Chen, C. Z. Zhang, and L. X. Han, "Kaolinite-urea intercalation composites," American Ceramic Society Bulletin, vol. 84, no. 12, pp. 9301-9305, 2005.

[23] F. Sher, "Crystal structure determination I," in Proceedings of the National Workshop on Crystal Structure Determination Using Powder XRD, Pakistan Institute of Engineering and Applied Sciences, Khwarzimic Science Society, August 2007.

[24] S. A. Speakman, Estimating Crystallite Size Using XRD, MIT Center for Materials Science and Engineering, 2014.

[25] E. H. J. Lugwisha and S. I. Siafu, "The properties of feldspathic dental porcelain from tanzanian aluminosilicate materials," International Journal of Development Research, vol. 4, no. 11, pp. 2260-2265, 2014.

[26] E. H. J. Lugwisha, "Identification of clay minerals of the eastern southern region of Lake Victoria by ethylene glycol and heat: X-ray diffraction and infrared spectroscopy studies," Tanzania Journal of Science, vol. 37, pp. 167-178, 2011.

[27] P. J. R. Uwins, I. D. R. Mackinnon, J. G. Thompson, and A. J. E. Yago, "Kaolinite: NMF intercalates," Clays and Clay Minerals, vol. 41, no. 6, pp. 707-717, 1993.

[28] S. Letaief and C. Detellier, "Clay-polymer nanocomposite material from the delamination of kaolinite in the presence of sodium polyacrylate," Langmuir, vol. 25, no. 18, pp. 1097510979, 2009.

[29] J. Gardolinsky, Interlayer Grafting and Delamination of Kaolinite, Christian-Albrechts-University, Kiel, Germany, 2005.

[30] P. Santos, Ciência e Tecnologia de Argilas, vol. 1, Edgard Blücher, São Paulo, Brazil, 2nd edition, 1989.

[31] D. Beaufort, A. Cassagnabere, S. Petit et al., "Kaolinite-todickite reaction in sandstone reservoirs," Clay Minerals, vol. 33, no. 2-3, pp. 297-316, 1998.

[32] U. Aroke and U. El-Nafaty, "XRF, XRD and FTIR properties and characterization of HDTMA-Br surface modified organokaolinite clay," International Journal of Emerging Technology and Advanced Engineering, vol. 4, no. 4, pp. 817-825, 2014.

[33] S. Olejnik, L. A. G. Aylmore, A. M. Posner, and J. P. Quirk, "Infrared spectra of kaolin mineral-dimethyl sulfoxide complexes," The Journal of Physical Chemistry, vol. 72, no. 1, pp. 241249, 1968.

[34] M. M. Dawley, A. M. Scott, F. C. Hill, J. Leszczynski, and T. M. Orlando, "Adsorption of formamide on kaolinite surfaces: a combined infrared experimental and theoretical study," The Journal of Physical Chemistry C, vol. 116, no. 45, pp. 23981-23991, 2012.

[35] C. O. Mgbemena, N. O. Ibekwe, R. Sukumar, and A. R. R. Menon, "Characterization of kaolin intercalates of oleochemicals derived from rubber seed (Hevea brasiliensis) and tea seed (Camelia sinensis) oils," Journal of King Saud UniversityScience, vol. 25, no. 2, pp. 149-155, 2013.

[36] C. Y. Heah, H. Kamarudin, A. M. Mustafa Al Bakri et al., "Study on solids-to-liquid and alkaline activator ratios on kaolin-based geopolymers," Construction and Building Materials, vol. 35, pp. 912-922, 2012.

[37] E. Balan, A. M. Saitta, F. Mauri, and G. Calas, "First-principles modeling of the infrared spectrum of kaolinite," The American Mineralogist, vol. 86, no. 11-12, pp. 1321-1330, 2001.

[38] T. H. Dang, B.-H. Chen, and D.-J. Lee, "Application of kaolinbased catalysts in biodiesel production via transesterification of vegetable oils in excess methanol," Bioresource Technology, vol. 145, pp. 175-181, 2013.

[39] Y. M. Liew, H. Kamarudin, A. M. Mustafa Al Bakri et al., "Processing and characterization of calcined kaolin cement powder," Construction and Building Materials, vol. 30, pp. 794802, 2012.

[40] A. Tironi, M. Trezza, E. Irassar, and A. Scian, "Thermal treatment of kaolin: effect on the pozzolanic activity," Procedia Materials Science, vol. 1, pp. 343-350, 2012.

[41] C. N. Banwell and E. M. McCash, Fundamentals of Molecular Spectroscopy, McGraw-Hill, 1994.

[42] K. Nakamoto, Infrared and Raman Spectra of Inorganic and Coordination Compounds, Wiley, 1997.

[43] R. M. Pope and E. S. Fry, "Absorption spectrum (380-700 nm) of pure water. II. Integrating cavity measurements," Applied Optics, vol. 36, no. 33, pp. 8710-8723, 1997.

[44] S. Y. Venyaminov and F. G. Prendergast, "Water $\left(\mathrm{H}_{2} \mathrm{O}\right.$ and $\left.\mathrm{D}_{2} \mathrm{O}\right)$ molar absorptivity in the $1000-4000 \mathrm{~cm}^{-1}$ range and quantitative infrared spectroscopy of aqueous solutions," Analytical Biochemistry, vol. 248, no. 2, pp. 234-245, 1997.

[45] A. Czarnecka, Preparation and Characterization of KaoliniteBased Nanocomposite Materials, University of Ottawa, 2013.

[46] J. G. Thompson and C. Cuff, "Crystal structure of kaolinite: dimethylsulfoxide intercalate," Clays \& Clay Minerals, vol. 33, no. 6, pp. 490-500, 1985.

[47] C. T. Johnston, G. Sposito, D. F. Bocian, and R. R. Birge, "Vibrational spectroscopic study of the interlamellar kaolinitedimethyl sulfoxide complex," The Journal of Physical Chemistry, vol. 88 , no. 24 , pp. 5959-5964, 1984.

[48] R. L. Frost, J. Kristof, G. N. Paroz, and J. T. Kloprogge, "Molecular structure of dimethyl sulfoxide intercalated kaolinites," The Journal of Physical Chemistry B, vol. 102, no. 43, pp. 8519-8532, 1998.

[49] E. Horváth, J. Kristóf, and R. L. Frost, "Vibrational spectroscopy of intercalated kaolinites. Part I," Applied Spectroscopy Reviews, vol. 45, no. 2, pp. 130-147, 2010.

[50] J. J. Tunney and C. Detellier, "Chemically modified kaolinite. Grafting of methoxy groups on the interlamellar aluminol surface of kaolinite," Journal of Materials Chemistry, vol. 6, no. 10, pp. 1679-1685, 1996.

[51] J. Matusik, E. Scholtzová, and D. Tunega, "Influence of synthesis conditions on the formation of a kaolinite-methanol complex and simulation of its vibrational spectra," Clays and Clay Minerals, vol. 60, no. 3, pp. 227-239, 2012.

[52] P. Larkin, Infrared and Raman Spectroscopy; Principles and Spectral Interpretation, Elsevier, 2011.

[53] P. H. Fischer and C. A. McDowell, "The infrared absorption spectra of urea-hydrocarbon adducts," Canadian Journal of Chemistry, vol. 38, no. 2, pp. 187-193, 1960. 
[54] Z. Piasek and T. Urbanski, "Infrared absorption spectrum and structure of urea," Bulletin de l'Académie Polonaise des Sciences. Série des Sciences Chimiques, vol. 10, no. 3, p. 113, 1962.

[55] H. Becher, "Infrared spectroscopic examination of the reaction products of urea and formaldehyde. I. Methylene ureas," Chemische Berichte, vol. 89, pp. 1593-1601, 1956.

[56] G. Rutkai, É. Makó, and T. Kristóf, "Simulation and experimental study of intercalation of urea in kaolinite," Journal of Colloid and Interface Science, vol. 334, no. 1, pp. 65-69, 2009.

[57] G. Barlow and P. Corish, "337. Infrared absorption spectra of some urea complexes," Journal of the Chemical Society, pp. 17061710, 1959.

[58] V. V. T. Padil, N. H. A. Nguyen, A. Ševců, and M. Černík, "Fabrication, characterization, and antibacterial properties of electrospun membrane composed of gum karaya, polyvinyl alcohol, and silver nanoparticles," Journal of Nanomaterials, vol. 2015, Article ID 750726, 10 pages, 2015.

[59] S. Vahur, "IR Spectra of Carbohydrates: Gum Arabic," 2014, http://tera.chem.ut.ee/IR_spectra/index.php?option=com_ content\&view $=$ article\&id=107\&Itemid $=77$.

[60] N. A. Almuslet, E. A. Hassan, A. S. A.-E. Al-Sherbini, and M. G. A. Muhgoub, "Diode laser $(532 \mathrm{~nm})$ induced grafting of polyacrylamide onto Gum Arabic," Journal of Physical Science, vol. 23, no. 2, pp. 43-53, 2012.

[61] C. Chakraborty, P. K. Sukul, K. Dana, and S. Malik, "Suppression of keto defects and thermal stabilities of polyfluorene- kaolinite clay nanocomposites," Industrial and Engineering Chemistry Research, vol. 52, no. 20, pp. 6722-6730, 2013.

[62] F. Vaughan, "Energy changes when kaolin minerals are heated," Clay Minerals Bulletin, vol. 2, no. 13, pp. 265-274, 1955.

[63] E. I. Pereira, F. B. Minussi, C. C. T. da Cruz, A. C. C. Bernardi, and C. Ribeiro, "Urea-montmorillonite-extruded nanocomposites: a novel slow-release material," Journal of Agricultural and Food Chemistry, vol. 60, no. 21, pp. 5267-5272, 2012.

[64] M. M. E. Costa, E. C. M. Cabral-Albuquerque, T. L. M. Alves, J. C. Pinto, and R. L. Fialho, "Use of polyhydroxybutyrate and ethyl cellulose for coating of urea granules," Journal of Agricultural and Food Chemistry, vol. 61, no. 42, pp. 9984-9991, 2013.

[65] C. Gary, D. A. Marc, R. F. Charles et al., "Identification of the properties of gum arabic used as binder in $7.62-\mathrm{mm}$ ammunition primers," Tech. Rep. ADA526429, US Army Armament Research, Development and Engineering Center, Picatinny Arsenal, NJ, USA, 2010.

[66] R. T. Emmet, Spectrophotometric Determination of Urea in Natural Waters with Hypochlorite and Phenol, AD 686 387, Naval Ship Research and Development Laboratory, Annapolis, Md, USA, 1969. 

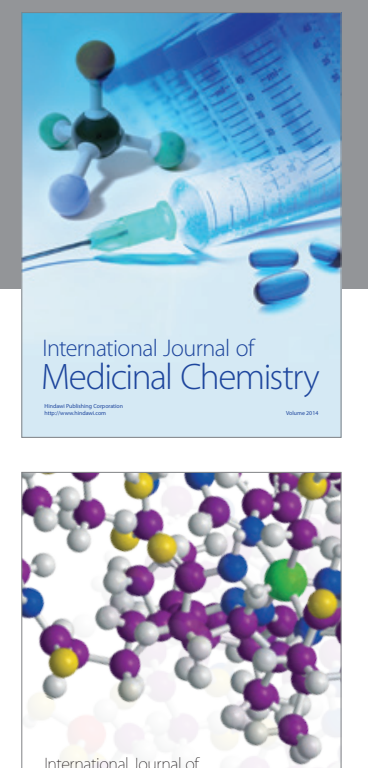

\section{Carbohydrate} Chemistry

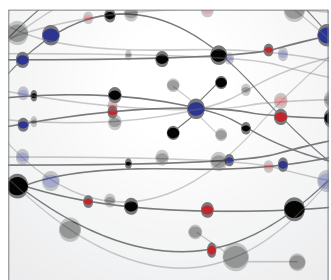

The Scientific World Journal
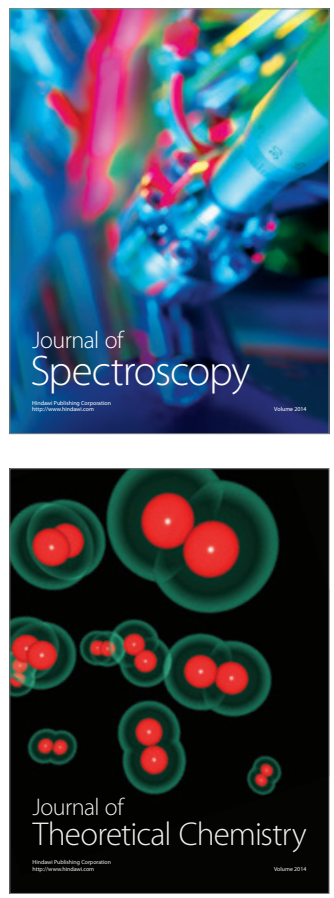
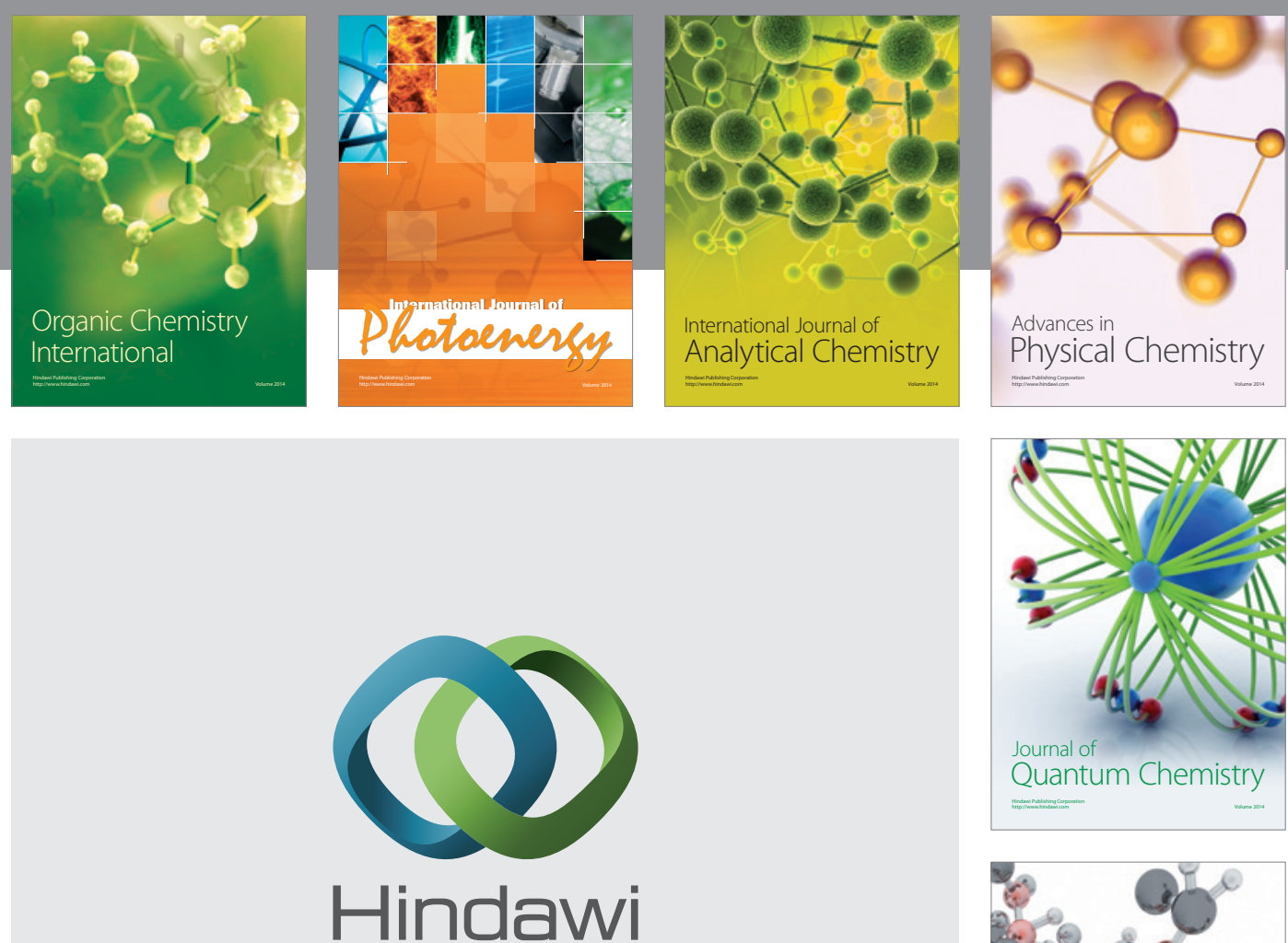

Submit your manuscripts at

http://www.hindawi.com

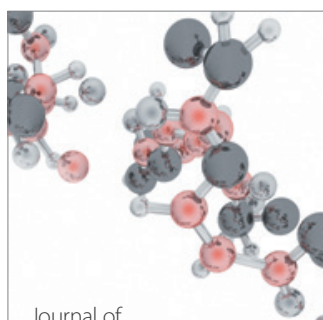

Analytical Methods

in Chemistry

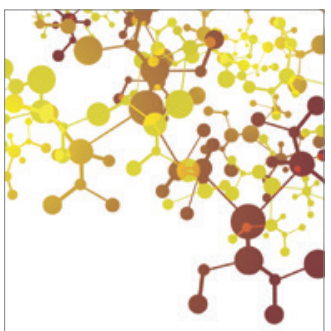

Journal of

Applied Chemistry

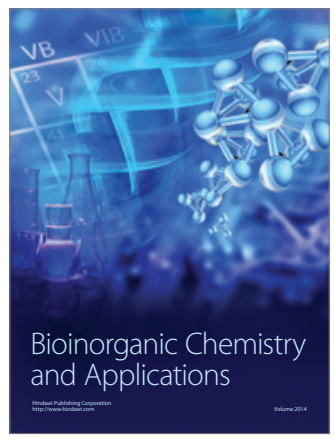

Inorganic Chemistry
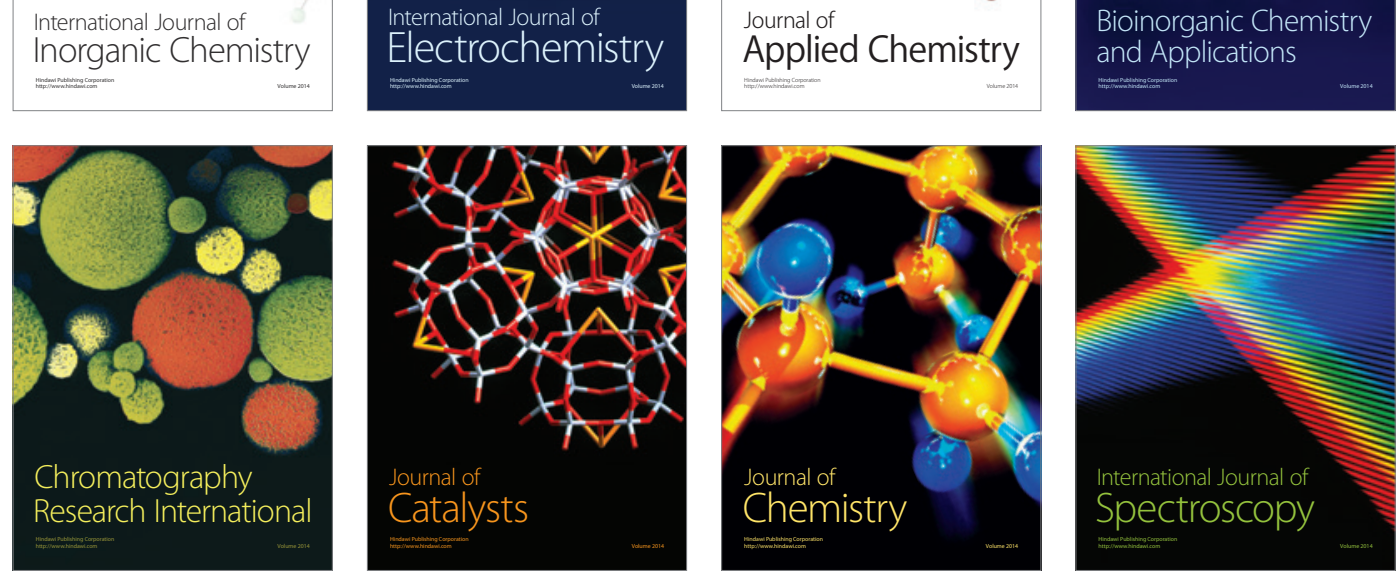